Engineering and Design

Elsevier Editorial System(tm) for Nuclear

Manuscript Draft

Manuscript Number: NED-D-16-00191R1

Title: Earthquake-induced crustal deformation and consequences for fault displacement hazard analysis of nuclear power plants

Article Type: Full Length Article

Corresponding Author: Dr. Paul Rizzo, Ph.D.

Corresponding Author's Institution: RIZzO Associates

First Author: Paul Rizzo, Ph.D.

Order of Authors: Paul Rizzo, Ph.D.; Aybars Gurpinar, Ph.D.; Leonello Serva, Ph.D.; Franz Livio, Ph.D.

Abstract: Readily available interferometric data (InSAR) of the coseismic deformation field caused by recent seismic events clearly show that major earthquakes produce crustal deformation over wide areas, possibly resulting in significant stress loading/unloading of the crust. Such stress must be considered in the evaluation of seismic hazards of nuclear power plants (NPP) and, in particular, for the potential of surface slip (i.e., probabilistic fault displacement hazard analysis PFDHA) on both primary and distributed faults.

In this study, based on the assumption that slip on pre-existing structures can represent the elastic response of compliant fault zones to the permanent co-seismic stress changes induced by other major seismogenic structures, we propose a three-step procedure to address fault displacement issues and consider possible influence of surface faulting/deformation on vibratory ground motion (VGM). This approach includes: a) data on the presence and characteristics of capable faults, b) data on recognized and/or modeled co-seismic deformation fields and, where possible, c) static stress transfer between source and receiving faults of unknown capability.

The initial step involves the recognition of the major seismogenic structures nearest to the site and their characterization in terms of maximum expected earthquake and the time frame to be considered for determining their "capability" (as defined in the International Atomic Energy Agency - IAEA Specific Safety Guide SSG -9). Then a GIS-based buffer approach is applied to identify all the faults near the NPP, possibly influenced by the crustal deformation induced by the major seismogenic structures. Faults inside these areas have to be tested for "capability" according to the same time window defined for the primary seismogenic structures.

If fault capability is confirmed or, eventually, cannot be assessed, the next step is to implement an approach based on the potential to affect the safety of the NPP site in terms of fault geometry, and potential displacement.

Finally, in the case where the fault can affect the safety of the site, the third step is the PFDHA or, in other words, the calculation of the annual probability of exceedance of the potential co-seismic fault displacement; this displacement is to be compared with the fault displacement threshold that will impact the safety of the NPP site. 
We also consider the effect of site vicinity tectonism on site vibratory ground motion and discuss an example in the light of the use of the GMPE.

Keywords: Faults, Geology, Fault Hazards, Capable Faults 
July 5, 2016

Project No. 169005

Dr. Yassin Hassan, Ph.D.

Editor-in-Chief

Nuclear Engineering and Design

\section{Earthquake-Induced Crustal Deformation and Consequences \\ for Fault Displacement Hazard Analysis of Nuclear Power Plants \\ Nuclear Engineering and Design \\ Ms. Ref. No.: NED-D-16-00191}

Dear Dr. Hassan,

Thank you and the two reviewers who have provided valuable feedback to our research and supplied us with notes and suggestions for improvement. We also note that one of the reviewers suggested that the paper can be accepted only as a 'technical note' and not a research paper. We will be happy to incorporate all the suggested changes that we believe are reasonable but we would like to insist on the publishing this work as a proper research paper (and not as a technical note). Therefore, before proceeding with the major modification that we will need to make, we would like to have assurance from you that it be considered to be published as a research paper.

Below are our arguments that respond to the major comments that we received. We would like to underline the following points that may have been misunderstood (by the first reviewer):

- InSAR is a technique well-validated by a large amount of studies (almost 20 years of data acquisition and field truthing) so we really don't think that a validation of the InSAR data itself should be posed under doubt and/or need to be validated by i.e., newly acquired geodetic data. In this sense we assume that all the data used in the paper would be 
considered as validated; moreover, for our analysis, we used only published data that, in turn, already underwent peer-review.

- The reviewer asks if all the InSAR data are newly acquired or already published: it is clearly written that we considered only already published data and a complete list of references is given in table.

- The reviewer also asks for a reference stating that coseismically deformed areas are correlated with earthquake magnitude: this is one of the results of this paper and it is part of the data analysis together with the static stress modeling. In this sense we underline that this is a research paper.

- In summary, we underline that the text starts from some original results, deriving from an analysis of InSAR data e.g. stress modeling, to propose an integrated approach to PFDHA with specific application to the nuclear industry where we see 'fault capability' issues arising both for new as well as existing site (e.g. Japan).

On the other hand, we agree that the text can be streamlined and better organized:

- We propose to provide a more detailed methodology section - We would produce a final workflow of the proposed methodology, summarizing the discussions.

If you agree that this work could proceed into the editorial route toward a publication as an original paper, we would like to proceed with these major revisions of the work, trying to fulfill the requests of both of the reviewers. If this is not possible, we will consider the possibility of retracting the paper.

Thank you very much in advance for your attention.

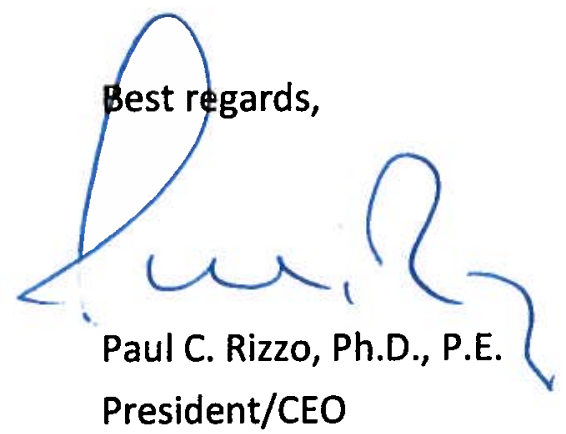

Cc: Aybars Gurpinar Leonello Serva Livio Franz 


\section{Highlights}

- We propose a three-step procedure to incorporate coseismic deformation and re-activation of pre-existing faults into PFDHA.

- If a NPP site is in the area possibly permanently deformed by future strong earthquakes, increased scrutiny is needed for local faults.

- Faults lying in the area potentially deformed by major earthquakes on regional seismogenic structures, share with the latter the same time window for assessing fault capability

- VGM variation may occur due to tectonism that has caused co-seismic deformation. 


\title{
Earthquake-induced crustal deformation and consequences for fault displacement hazard analysis of nuclear power plants
}

\author{
Aybars Gürpinar ${ }^{1}$, Leonello Serva $^{2,}$ Franz Livio $^{3}$, Paul C. Rizzo ${ }^{4, *}$ \\ ${ }^{1}$ Nuclear \& Risk Consultancy, Anisgasse 4, 1221 Vienna, Austria, aybarsgurpinar2007@yahoo.com \\ ${ }^{2}$ Instituto Superiore per la Protezione e la Ricerca Ambientale, Via Curtatone 3, 00185, Rome, Italy, 1serva@alice.it \\ ${ }^{3}$ Dipartimento di Scienza ed Alta Tecnologia, Università degli Studi dell'Insubria, Via Velleggio, 11, 22100 Como, Italy, \\ franz.livio@uninsubria.it \\ ${ }^{4}$ RIZZO Associates, 500 Penn Center Blvd., Suite 100, Pittsburgh, Pennsylvania 15235, USA, paul.rizzo@ @rizzoasoc.com \\ *Corresponding author. Tel.: +1-412-825-2021; fax: +1-412-856-9749 \\ Email address: paul.rizzo@ rizzoassoc.com
}




\section{Introduction}

Earthquake-induced permanent ground deformation can significantly impact the safety of Nuclear Power Plants (NPPs) in a twofold way. The first issue is the potential for ground rupture or fault displacement at the site: the fault capability (i.e., the potential for surface or near-surface faulting, ground deformation, or folding, sensu IAEA, 2010). This factor is among the important exclusionary criteria for the siting of nuclear installations (e.g., CFR, 1962; IAEA, 2010; ANSI/ANS-2.30, 2015) and great care is taken to avoid siting NPPs that could be affected by such ground behavior. The second issue relates to the impact of vibratory ground motion (VGM) associated with tectonic structures in the site vicinity (and possibly within the site area), and how this may contribute to what is generally called "site effects."

Both issues definitely rely on predicting the location and amount of surface faulting given a future strong earthquake in the proximity of the plant (Fault Displacement Hazard analysis, FDHA hereafter). Even if significant advances have been made for locating and mapping the primary fault, this task still remains problematic in the case of secondary ruptures (i.e., secondary or distributed faulting (DF) and for "distributed faults," defined as ruptures that occur on faults in the proximity of a principal seismogenic structure, in response to the displacement on the primary fault (ANSI/ANS-2.30, 2015). Present probabilistic approaches (e.g., Youngs et al. 2003; Petersen et al. 2011; Quittmeyer et al. 2016) may underestimate the frequency of occurrence of secondary faults, especially far from the primary structure, as demonstrated by recent case studies (e.g., Napa Valley earthquake, Baize \& Scotti, 2015; L’Aquila earthquake, Livio et al, 2016).

InSAR data from recent earthquakes clearly show that major earthquakes cause significant crustal strain over wide areas, resulting in permanent stress transfer to surrounding rock volume and pre-existing faults (i.e. Coulomb or Static Stress Transfer, King, et al. 1994; Stein, 1999). These structures, in turn, can experience coseismic or post-seismic reactivation, resulting in a localized rupture of the surface that may be of significant concern for the siting of an NPP. Relatively small Coulomb stress changes can potentially induce slip on a secondary fault (Stein, 1999) and the elastic response of compliant faults to the permanent co-seismic stress change may exceed the effect of dynamic triggering or regional stress field, resulting also in an induced motion on DF opposite to the long-term geologic slip (Fialko et al., 2002).

In this paper, we first explore the shortcomings from current PFDHA procedure, at the light of recent earthquakes (Chapter 2). Then, we consider the 2009, L'Aquila earthquake (Mw 6.3) case study (Chapter 3) to explore possible regressions on the occurrence of DF, other than a mere distance-based method (i.e., calculating loading due to static stress transfer and performing a curvature analysis). Finally, a performance based risk informed approach is proposed for FDHA (Chapter 4). The methodology is based on axiomatic informed engineering judgement and partially relies on the assumption that a strong spatial correlation between DF and co-seismically-induced strain, as recently shown by several InSAR-derived datasets, exists.

In addition, we consider the potential effects of site vicinity tectonism on site vibratory ground motion and discuss an example through the use of a GMPE. Present-day ground motion prediction equations (GMPE's) have a level of uncertainty that has to be addressed, both aleatory and epistemic, particularly near a rupture. If tectonic features exist in the site vicinity, the profession must account for this uncertainty.

\section{Shortcomings with the database for probabilistic fault displacement hazard analysis and new insights from InSAR data.}

It is well known that only earthquakes above a certain magnitude typically produce surface rupture, while all macro-earthquakes produce crustal deformation (e.g. events whose $\mathrm{M}>3.0$ ). For example, the $\mathrm{M}=3.5$ earthquake that occurred in June 1994 near L'Aquila, Italy, resulted in a deformation of 1 micron, measured in the underground Gran Sasso physics laboratories (Serva, 1995). This crustal deformation, together with the VGM generated by the earthquake, produces significant effects on the ground. These effects are catalogued in the Earthquake Environmental Effects (EEE) Global Catalogue of Earthquake Environmental Effects (www.eeecatalog.sinanet.apat.it), which supports the definition of the Environmental Seismic Intensity Scale (i.e., ESI 2007; Serva et al., 2016).

Regarding primary faulting, Figure 2.1 represents the state of the science for correlation between Mw and probability of primary surface faulting (Youngs et al., 2003; Moss \& Ross, 2011). Variable lower-threshold Mw values for surface faulting can be assessed, depending on different regression datasets and fault kinematics. It is clear that the probability of primary surface faulting can be significant for Mw values between 5.5 and 6.0. 


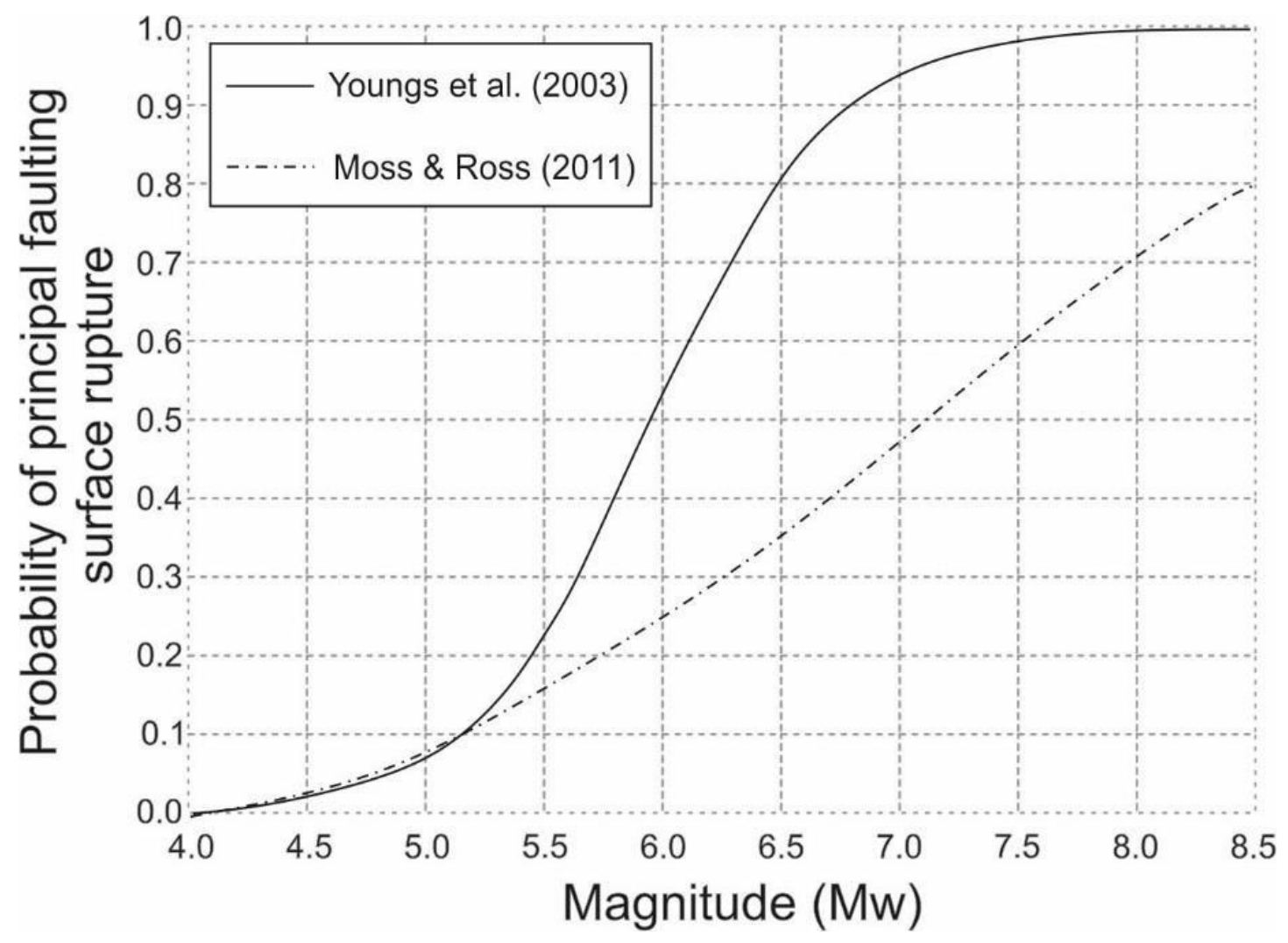

Figure 2.1. Probability curves for primary surface rupture for all slips (Youngs et al., 2003; mainly normal and strike-slip faults) and thrust faults (Moss \& Ross, 2011). Note that for a given magnitude, the probability of reverse rupture is significantly lower than that for other rupture types.

Assessment of displacement for DF is somewhat more complicated. In Figure 2.2 and Figure 2.3, the currently available data regarding slip on DF and the conditional probability of slip are respectively given as a function of distance from the primary fault (e.g., Youngs et al., 2003; Petersen et al., 2011; Takao et al., 2013). The dataset of Petersen et al. (2011) is derived from observations on steeply dipping, strike-slip faults of Mw 6.5 - 7.6, whereas the distribution considered by Youngs et al. (2003) is developed from a dataset mainly composed of normal faults. Takao et al. (2013) analyzed data from reverse and strike-slip faults in Japan.

a)

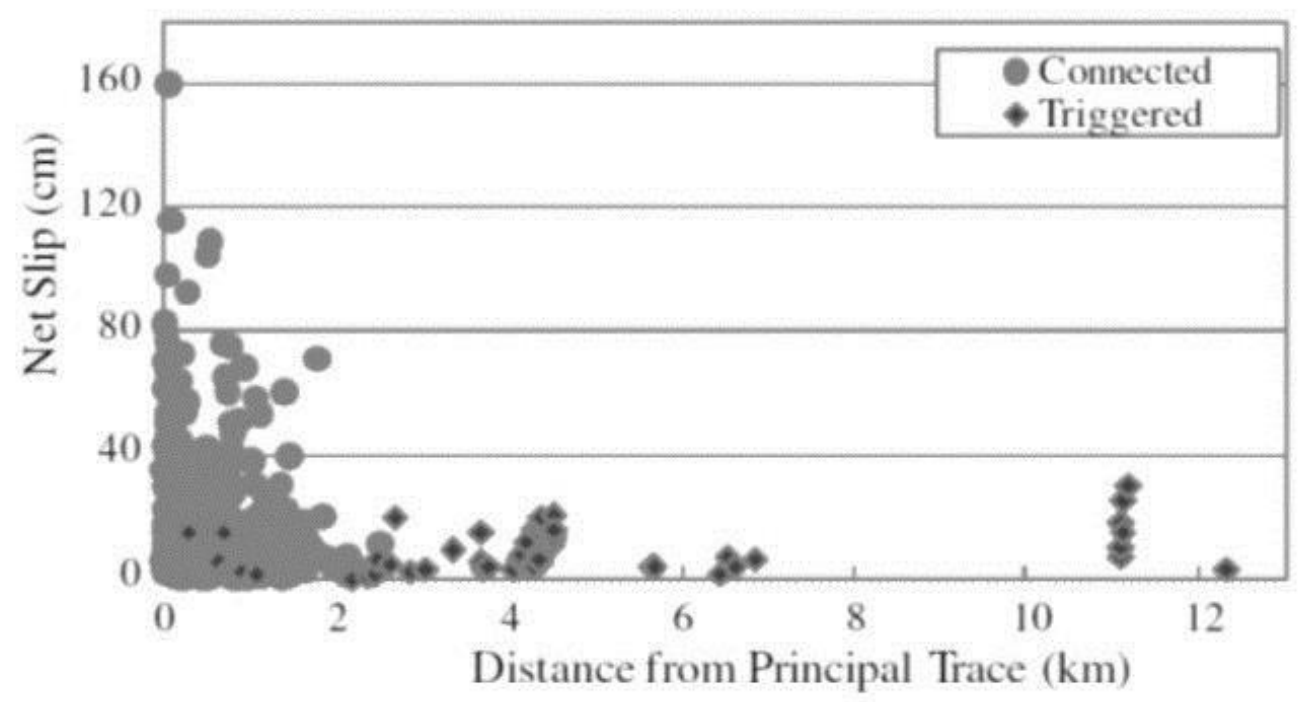


b)

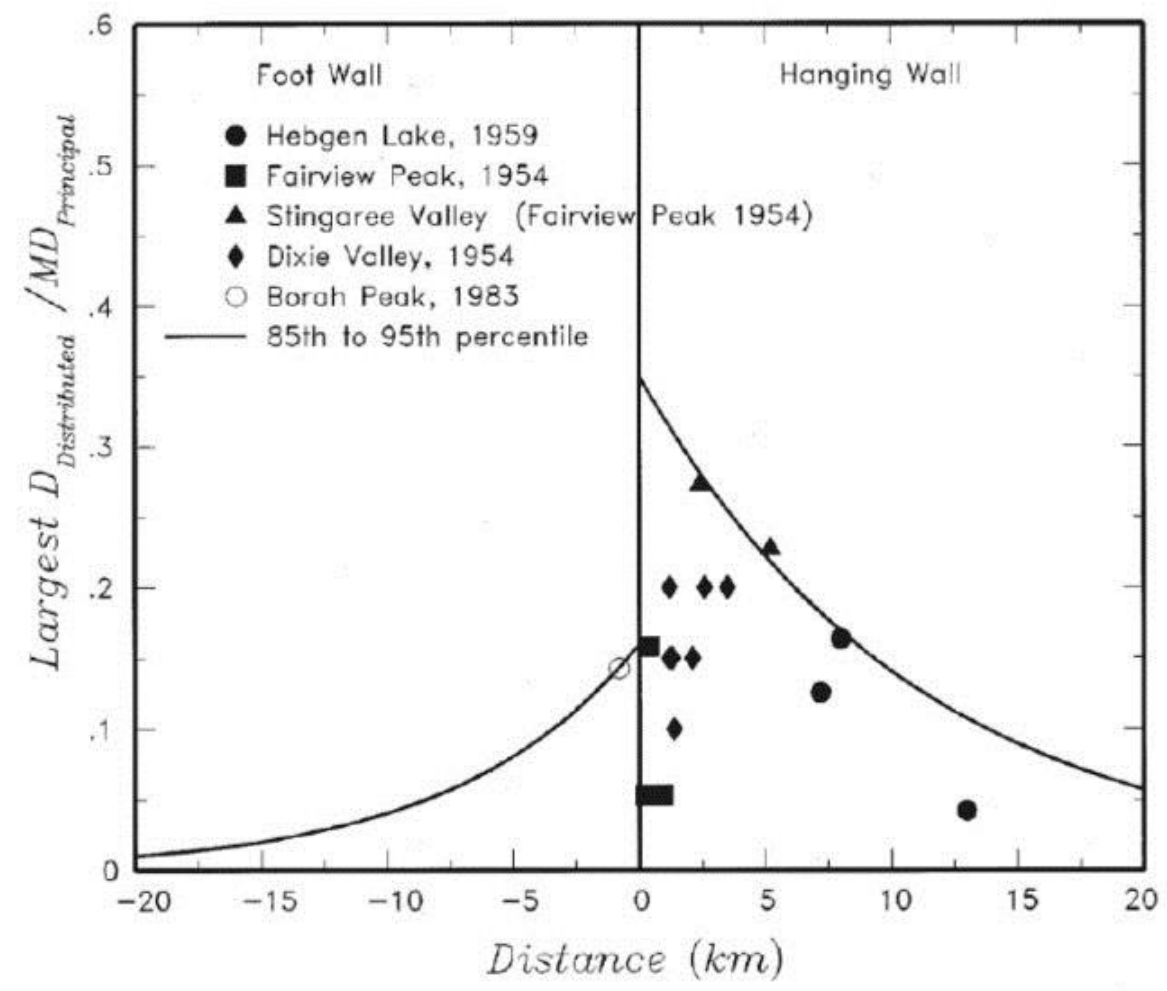

Figure 2.2. Slip on DF as a function of distance from the principal fault. Dataset for a) strike-slip faults (Petersen et al., 2011) and b) normal faults (Youngs et al., 2003).

Petersen et al. (2011) conclude that the hazard for off-fault ruptures is much lower than the hazard near the fault. Nevertheless, the data indicate that displacements up to 35 centimeters $(\mathrm{cm})$ can be triggered on adjacent faults at distances of 10 kilometers $(\mathrm{km})$ or more from the primary fault and with a meter-scale offset on the primary fault. 
a)
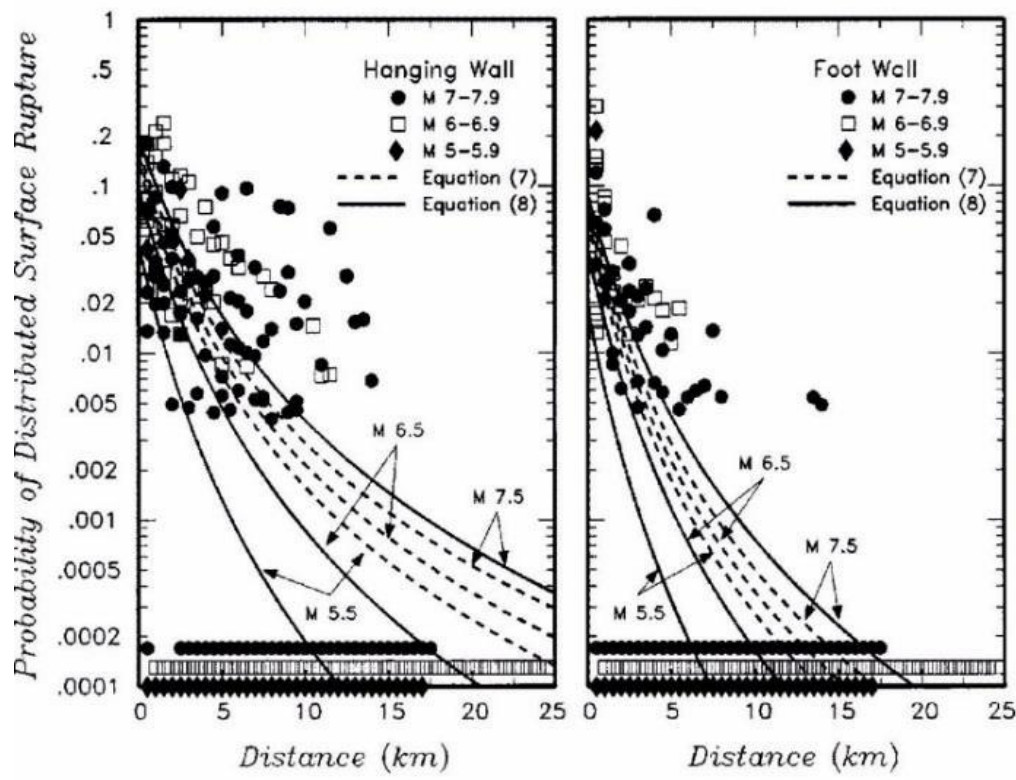

b)

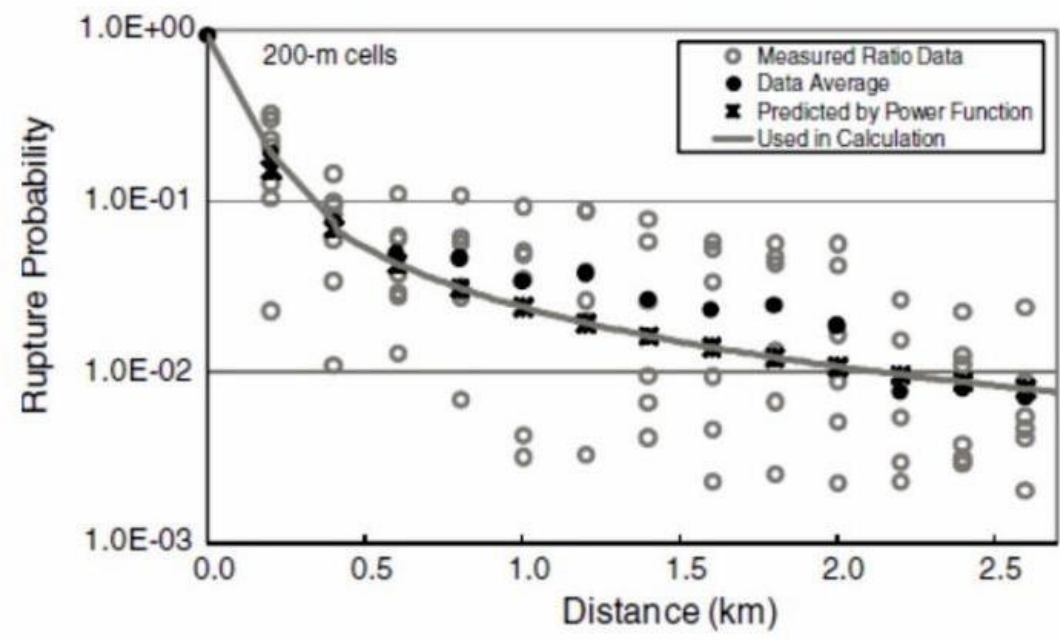




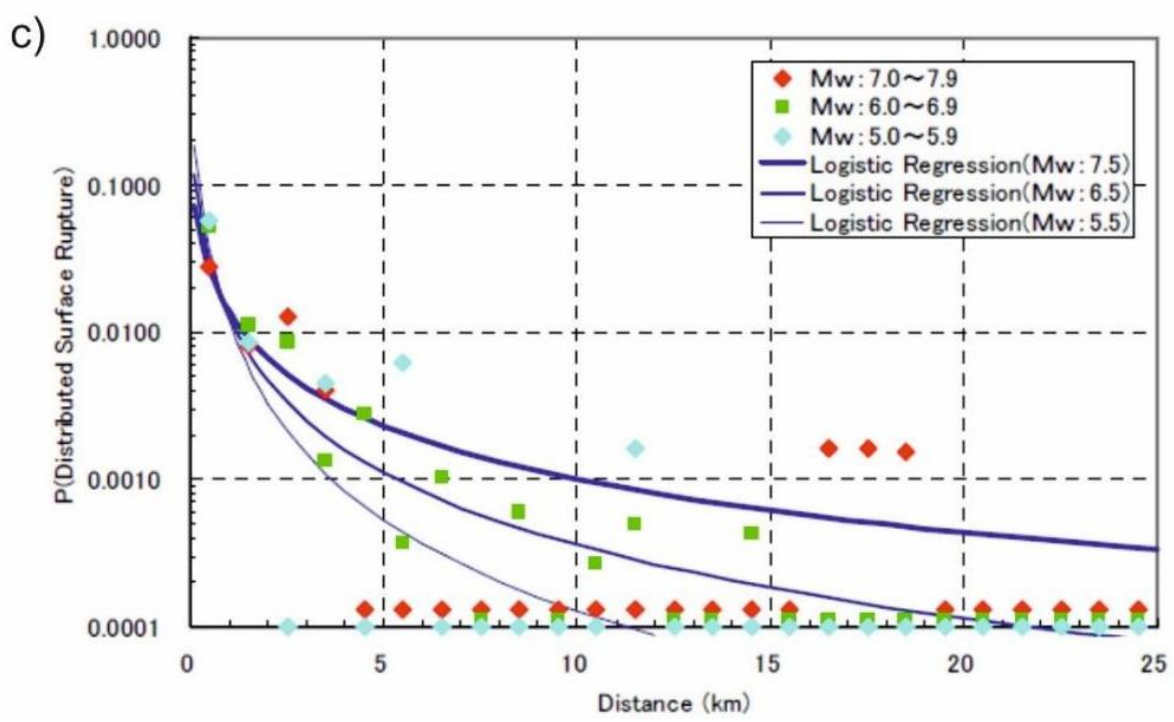

Figure 2.3. Probability of slip for DF as a function of distance from the principal fault. Data are for a) normal faults (Youngs et al., 2003), b) strike-slip faults (Petersen et al., 2011), and c) reverse and strike-slip faults in Japan (Takao et al., 2013).

The aforementioned probabilistic models, even if well-based, are biased by epistemic uncertainties, resulting from unknown factors varying from one earthquake to another (Youngs et al. 2003). In particular, the predictive power of these models is challenged for areas far from the primary structure, where a higher occurrence of DF has been highlighted during recent earthquakes (e.g., the 2014 South Napa Valley earthquake, Mw 6.0, Baize and Scotti, 2015 and the 2009 L'Aquila earthquake, Mw 6.3, Livio et al., 2016). We suggest that some of the uncertainty has to be ascribed to deterministic factors commonly referred to as the geologic and stratigraphic setting of the faulted area (i.e., depth of the propagating fault, thickness of the brittle layer, fault geometry, basin architecture, etc.) and assume that a possible approach in predicting the occurrence of DF can be based on the overall co-seismic deformation field associated to a certain slipping fault. Such a co-seismic deformation field, well imaged by remote sensing (i.e. InSAR data), is spatially correlated with DF also in areas far from the primary rupture (Livio et al., 2016), partially explaining an occurrence of DF more frequent than predicted from distance-based regressions. Earthquake-induced permanent strain can in fact result in the reactivation of preexisting structures as compliant faults accommodating elastic deformation or in the promotion of new localized ground breaks.

Moving from this assumption, we firstly compare probabilistic models of occurrence of DF with the coseismic deformation field of three single-earthquake events. Earthquake co-seismic surface deformation, detected through InSAR data, is compared in cross-section with probability curves for DF. Selected earthquake-induced displacement fields are shown relative to a thrust, normal, or strike-slip faulting event whose remotely detected line of sight (LOS) displacement fields or, if available, real displacement components are known (Figure 2.4, Figure 2.5, and Figure 2.6, respectively). We use the probability curves modeled by Youngs et al (2003), which are fitted on the corresponding earthquake magnitude. 


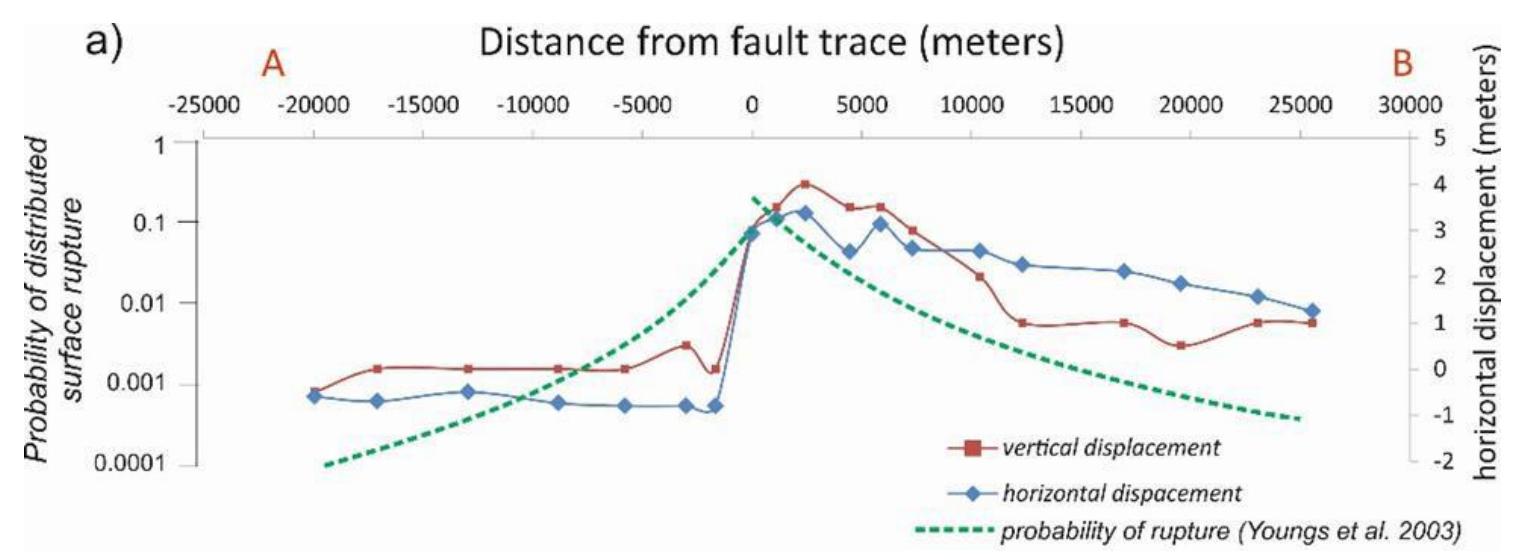

b)

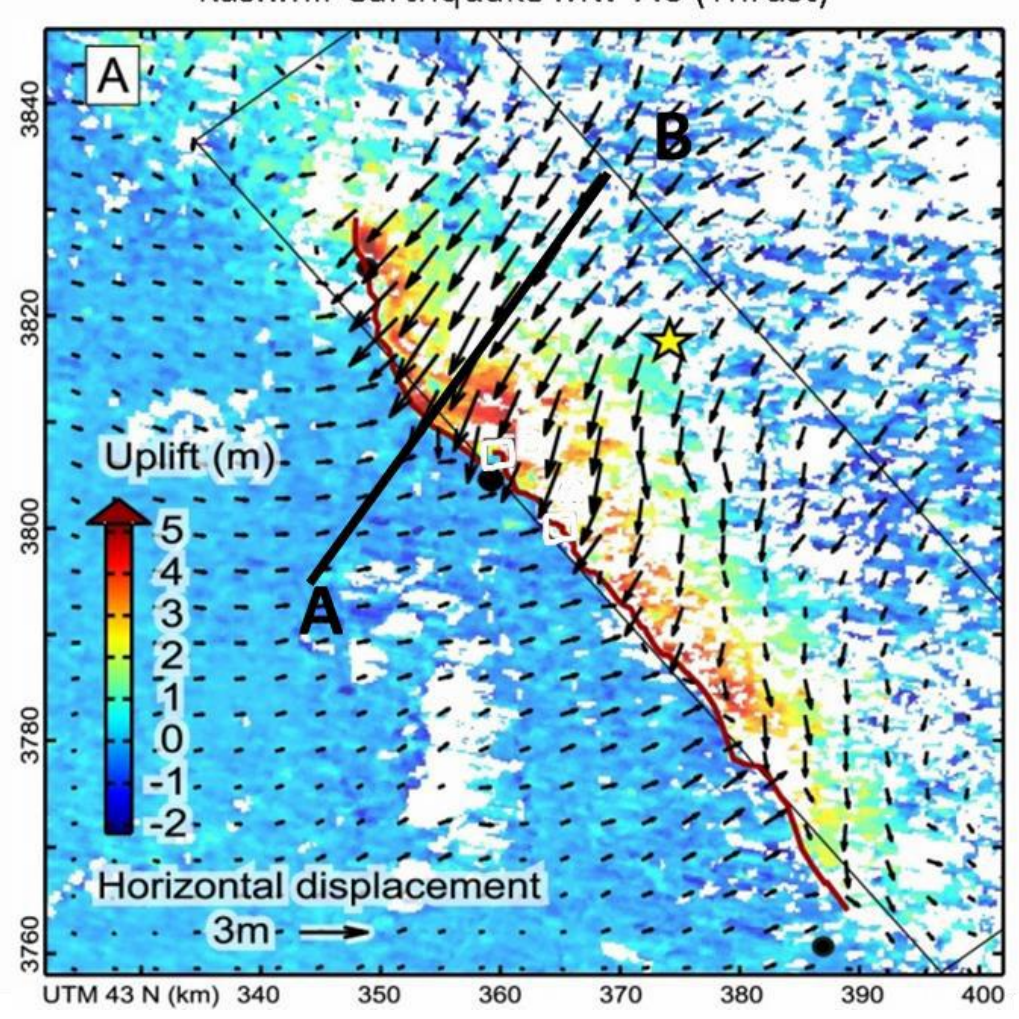

Figure 2.4. Co-seismic surface deformation that occurred during the $2005 \mathrm{Mw} 7.6$ Kashmir Earthquake: a) plot of the horizontal and vertical displacement components and probability curve for DF (Youngs et al., 2003) versus distance from primary fault; b) map view of the modeled In-SAR-derived, unwrapped surface deformation that show vectors for azimuth and range of displacement, and the color gradient shows the vertical deformation (modified after Pathier et al., 2006). 
a)

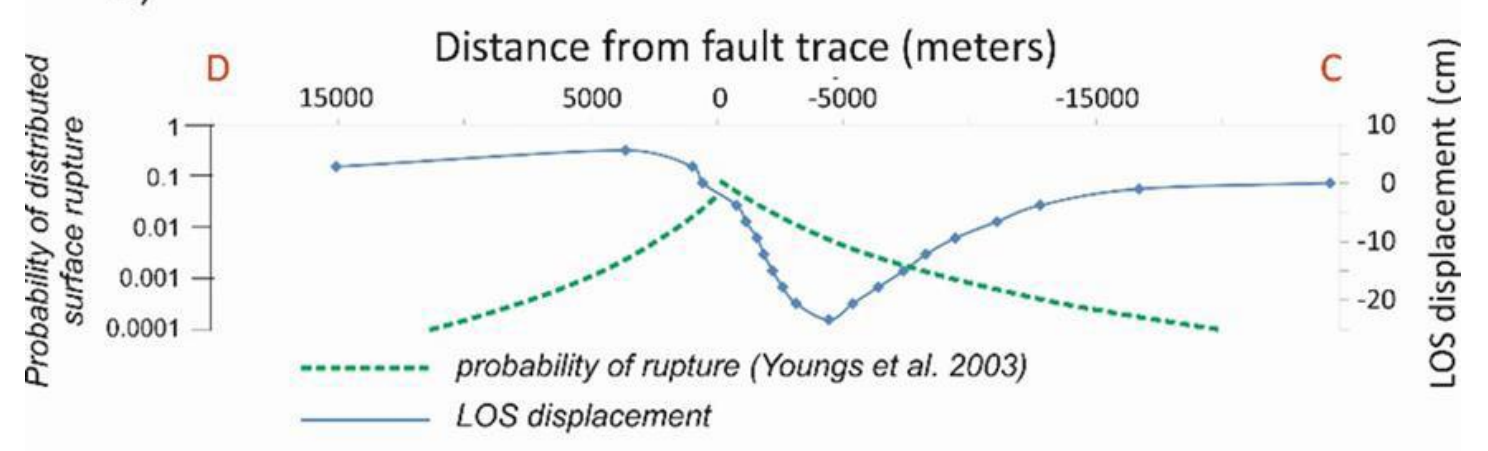

b)

L'Aquila earthquake Mw 6.3 (Normal fault)

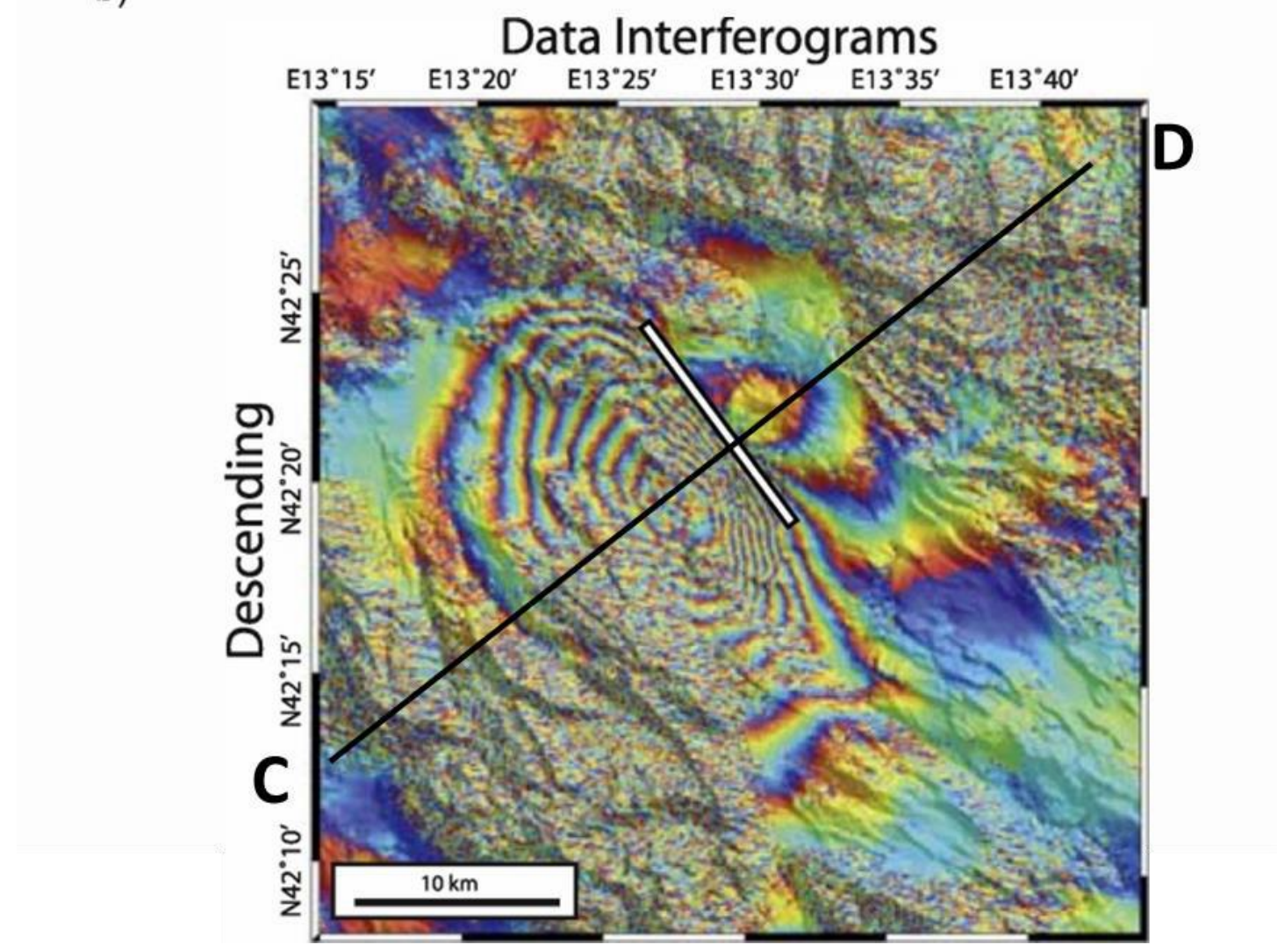

Figure 2.5. Co-seismic surface deformation that occurred during the Mw 6.3 L'Aquila Earthquake: a) plot of the LOS displacement and probability curve for DF (Youngs et al., 2003) versus distance from primary fault; b) map view of the modeled In-SAR- derived, wrapped surface deformation (modified after Walters et al., 2009). 


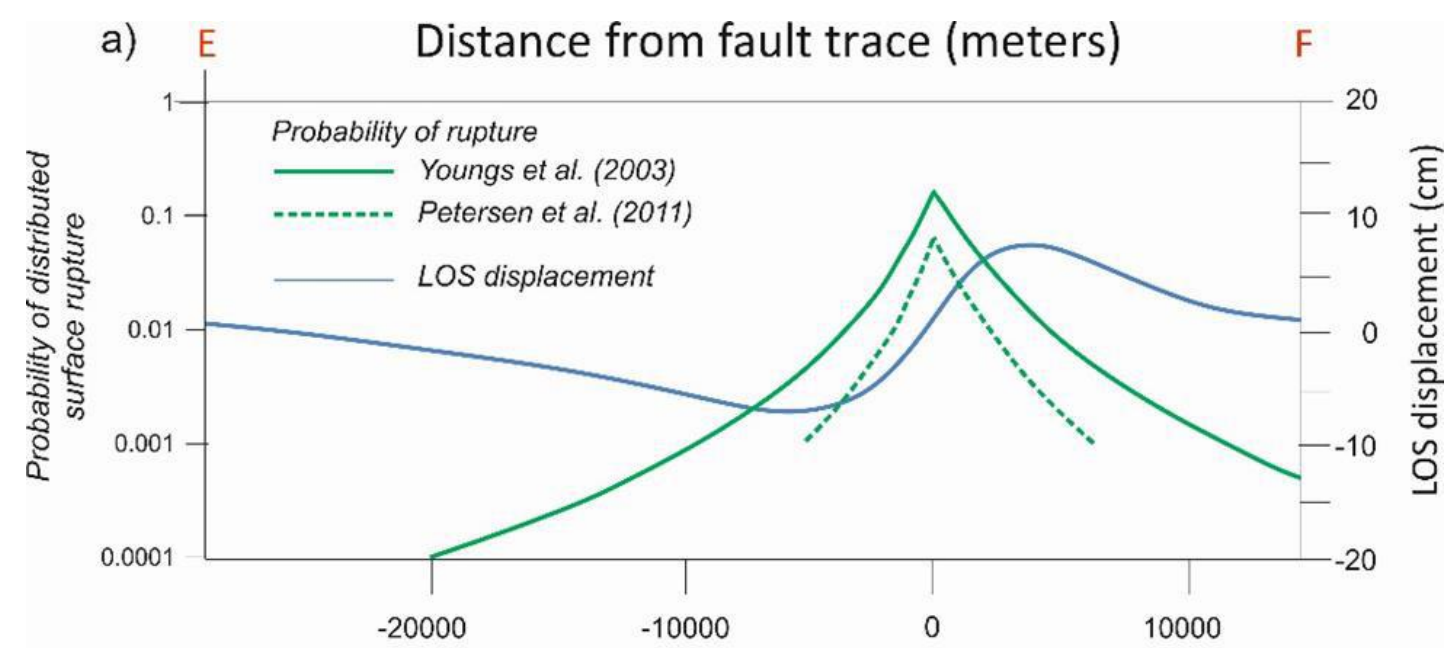

b)

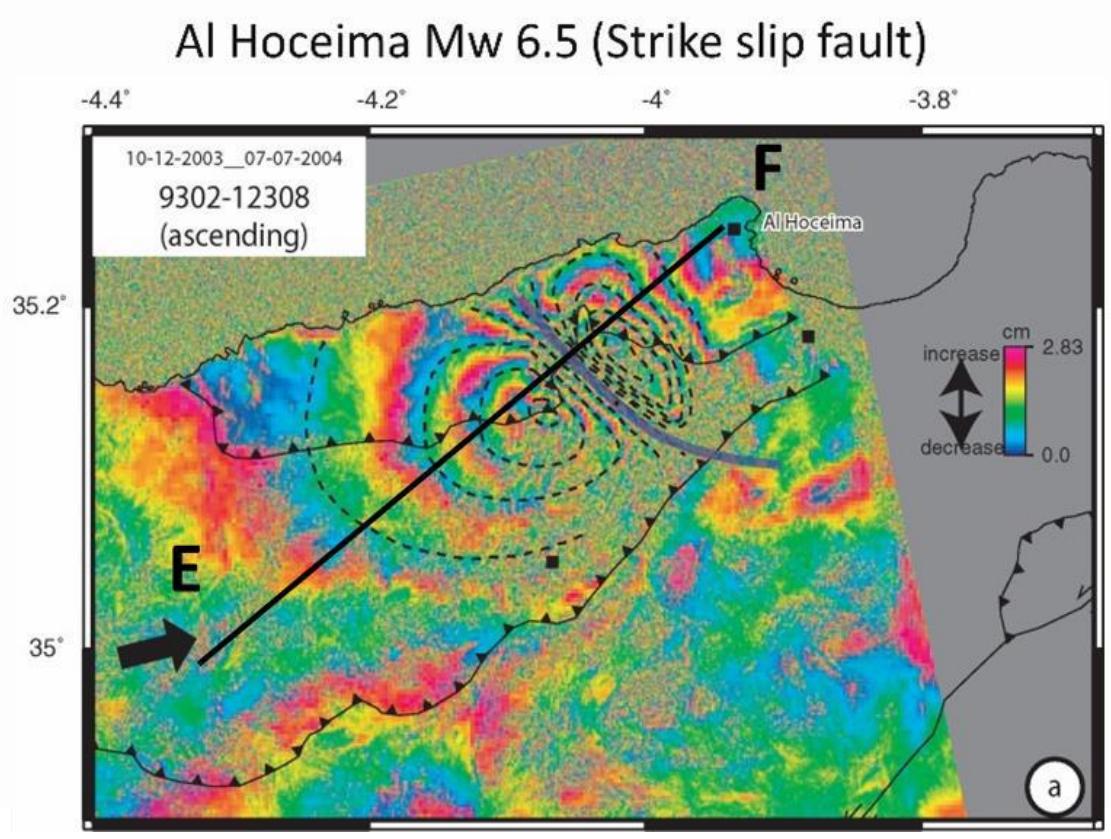

Figure 2.6. Co-seismic surface deformation that occurred during the Mw $6.5 \mathrm{Al}$ Hoceima Earthquake: a) plot of the LOS displacement and probability curves for DF (Youngs et al., 2003; Petersen et al., 2011) versus distance from primary fault; b) map view of the modeled, InSAR-derived, wrapped surface deformation (modified after Cakir et al., 2006).

It is worth noting that there is a general fit of the predicted probability of occurrence for DF with the coseismic displacement field. Even if the probability of occurrence is predicted only within $5 \mathrm{~km}$ of the primary fault, the displacement profiles show that a significant fraction of surface deformation is also induced at greater distances. Probabilistic curves are constrained by data only down to a probability of $10^{-2}-10^{-3}$ (Fig. 2.3a) and further extrapolation down to values as low as $10^{-4}$ is purely theoretical. Moreover, the distribution of the original data on which probabilistic relations were fitted (Fig. 2.3a) show that several DF occurred far from the primary rupture, with a relatively high frequency.

A good example in this sense comes from the $2007 \mathrm{Mw} 6.8$ Niigataken Chuetsu-oki Earthquake that affected the Kashiwazaki-Kariwa NPP in Japan (IAEA, 2008). The interferograms reveal considerable deformation in a region of active folding, $15 \mathrm{~km}$ east of the earthquake epicenter (Figure 2.7). The 1.5-kmwide by $15-\mathrm{km}$-long band of uplift is located along the anticline axis of a Neogene Period fold, very close to the NPP.

Because of the presence of the NPP, potentially capable faults were mapped in the area. The faulting/fracturing on the ground (e.g. Figure 2.8) were carefully compared with a levelling survey before the earthquake occurred (Figure 2.9). The levelling survey was performed in the area of the plant's vicinity. These investigations were performed by the Tokyo Electric Power Company, Inc. (TEPCO), the owner and operator of the Kashiwazaki-Kariwa NPP, to understand the behavior of the faults during the earthquake and also to investigate the possibility that their reactivation may have contributed to the anomalously high ground motion values recorded at the southern part of the site. 
The majority of the ground deformation manifested as decimeter-scale fractures with dominant orientations that strike parallel to the walls of NPP structures in the site area. Only a few of the fractures trend obliquely to these walls. All of these features have been analyzed to determine whether they are related to potential deep faults, with special consideration given to the well-known Madonasaka reverse fault.

The ground deformation has been interpreted by TEPCO as differential settlement generated by either compaction or liquefaction of the sediments used to backfill the excavated area in preparation for construction of the NPP. While this may be true in part, the data suggest that it is difficult to rule out the possibility of tectonically-induced displacement on these structures (Figure 2.9).

a)

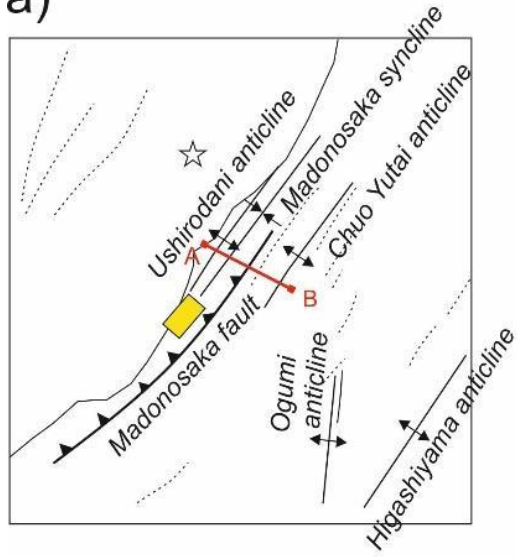

d)

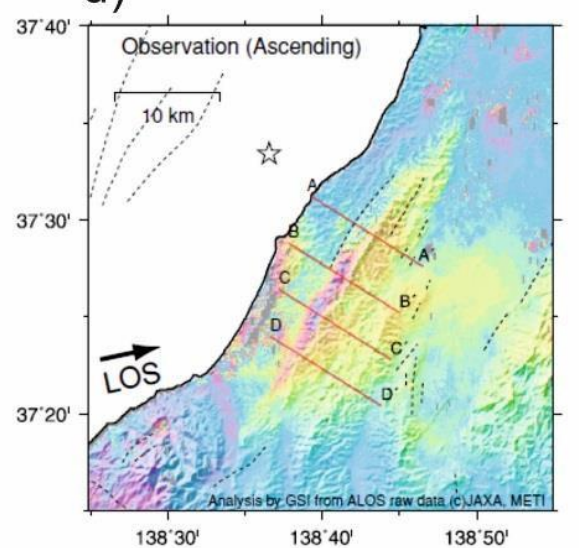

b)

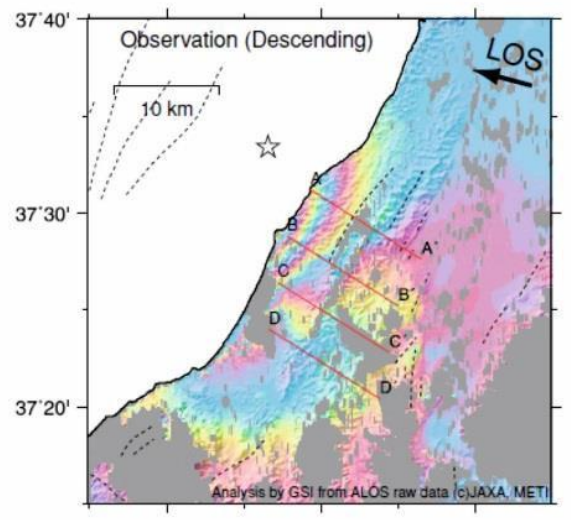

c)

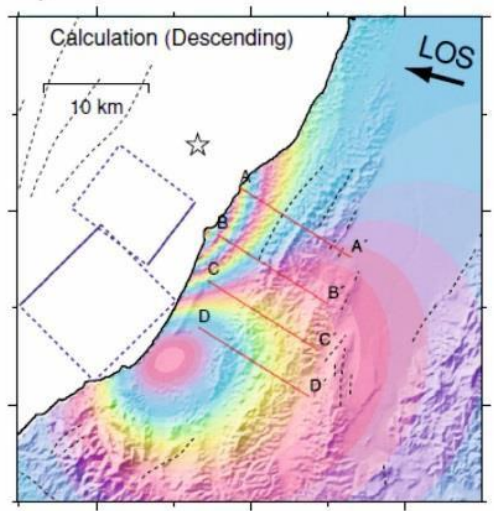

e)

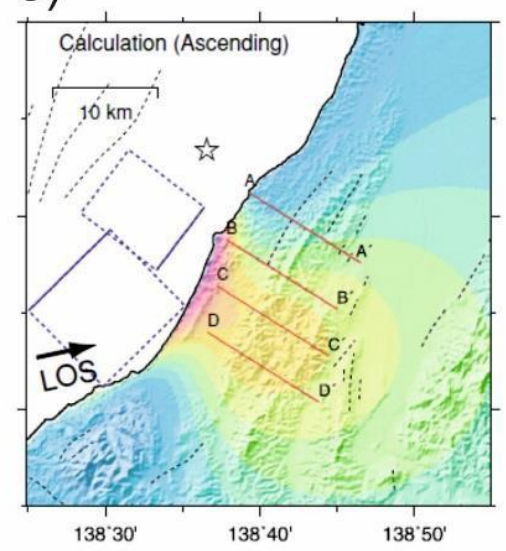

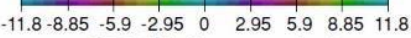

LOS Displacement $(\mathrm{cm})$

Figure 2.7. InSAR interferograms showing the displacement of the 2007 Niigataken Chuetsu-oki Earthquake: (a) Schematic structural map; the thin, dashed lines denote active fault traces (Research Group for Active Faults of Japan, 1991), and axial planes or hinge axes of synclines and anticlines are reported. The yellow rectangle indicates the approximate location of observed secondary faulting/fracturing (cfr. Figure 2.8). Images (b) and (d) present the interferograms formed from the descending and ascending orbit respectively; the dotted rectangle shows the fault location obtained through a best-fit model (solid line on the rectangles shows the upper edge of the fault). Images (c) and (e) are modeled interferograms calculated using the fault model (modified after Nishimura et al., 2008). 

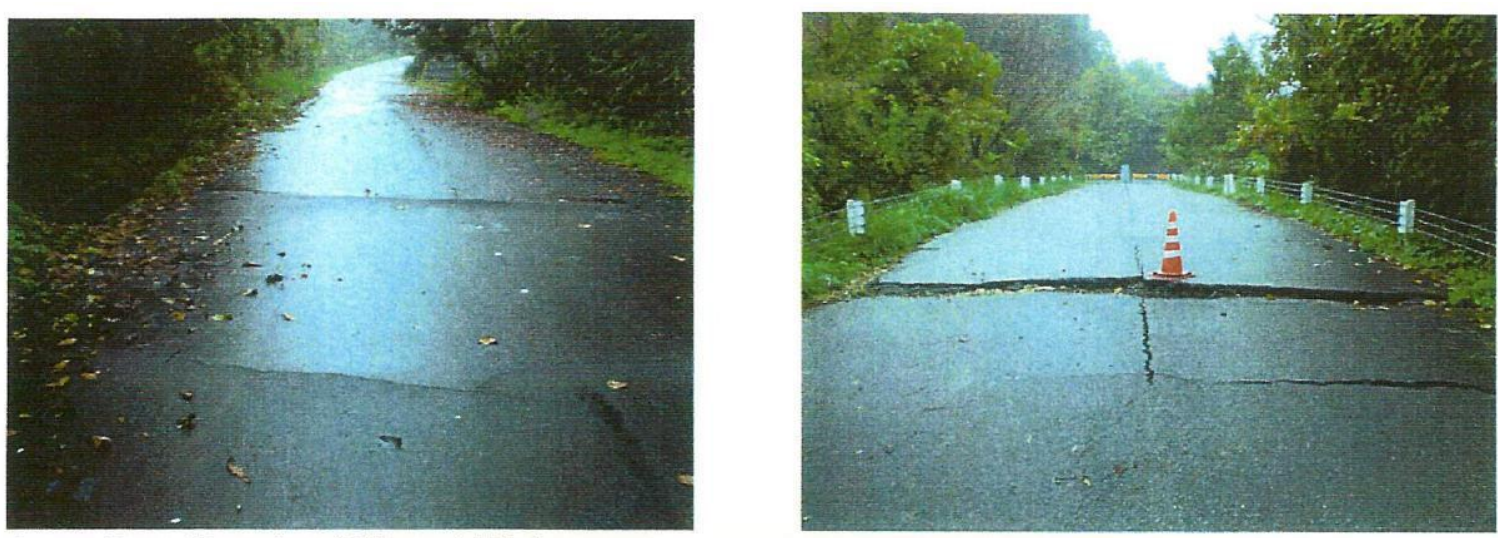

Figure 2.8. Image shows an example of the faulting/fracturing that occurred in the Kashiwasaki- Kariwa NPP site vicinity. Figure 2.7a identifies the location of the area affected by these secondary deformations.

a)
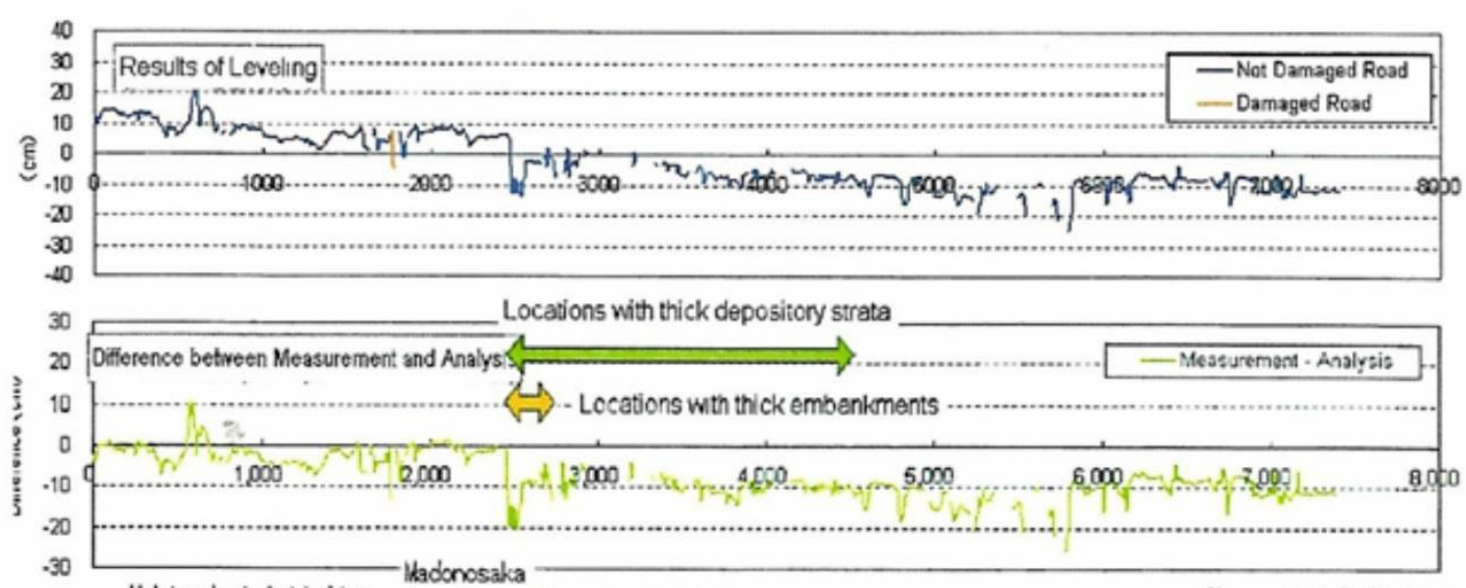

b)

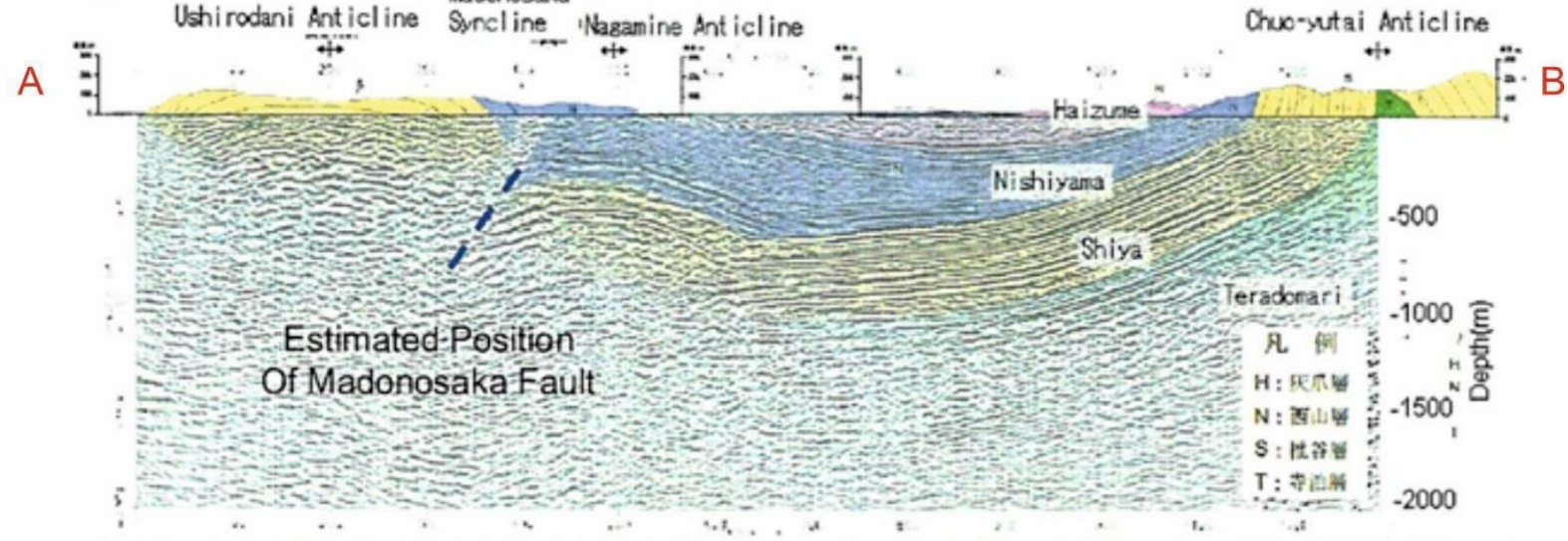

Figure 2.9. a) Levelling measurements in the Kashiwasaki-Kariwa NPP site vicinity, across the Madonosaka Fault: b) geologic cross section of the area (Figure 2.7a gives section trace). 
The movement of these faults is not reported in any publication related to the post-earthquake studies; it was disclosed only because of the detailed field surveys required by the NPP in the area. This suggests the possibility that other faults may have moved during this earthquake, but were never studied in detail.

If DF can occur at relatively great distances from the primary structure, the next question is how far a primary faulting can induce DF. Once again, we move from the assumption that DF is primarily controlled by a response to crustal strain and/or stress. It is generally accepted, and confirmed by many case studies, that the size and shape of the area affected by co-seismic deformation depends on the earthquake focal depth, faulting type, magnitude, and the size of the rupture at the hypocenter. Figure 2.10 (modified after Livio et al. 2016) shows the correlation between moment magnitude ( $\mathrm{Mw}$ ) and the area of co-seismic deformation as detected by InSAR. Areas of the deformed sectors located in both the hanging wall and in the footwall of the primary fault were measured. Our calculations considered the area enclosed by the most external coherent fringe. An envelope curve has been drawn where the same fringe was separated by incoherent signals (Figure 2.10b).

Averaged area values were considered in cases in which the location of the most external coherent fringe was debated (Figure 2.10b). It is clear that the total area affected by co-seismic deformation can be considered a good proxy for earthquake magnitude. Although focal depth and faulting type remain important parameters, they do not significantly affect the overall log- linear relationship of the regressed variables (Livio et al., 2016).

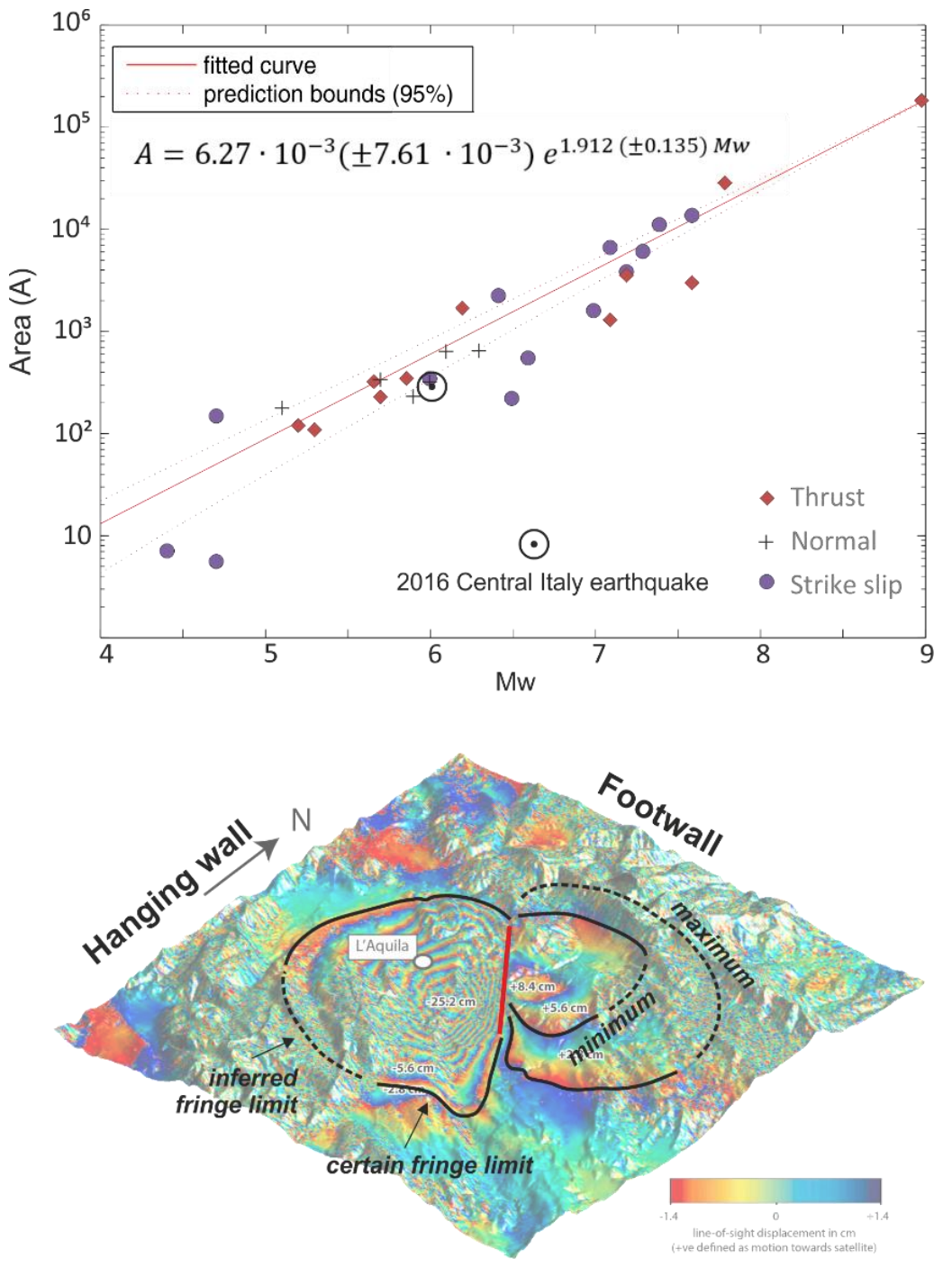

a)

b)

Figure 2.10. a) Regression between $\mathrm{Mw}$ and total area of deformation $\left(\mathrm{Km}^{2}\right)$ - the recent 2016 Central Italy earthquake, not included in the regression, is also reported showing a good accordance with predicted values; b) assumed method for area calculation: typical observed 
If we assume that DF is primarily induced by co-seismic deformation and promoted by induced static stress changes, we can also define the maximum extent of the area possibly affected by DF, given a certain maximum expected earthquake Magnitude.

Another important observation is that the occurrence of DF in several case histories seems to suggest a more complicated relationship between primary fault and DF location, rather than a simple distance-regressed function. How can these observations be interpreted?

We suggest that DF can be spatially correlated with the permanent dislocation induced in the rock volume by co-seismic movement. Two possible correlations are proposed: the first infers that co-seismic deformation induces a permanent stress transfer on receiving pre-existing faults (i.e., Coulomb Static Stress Transfer, e.g., Stein, 1999), possibly promoting DF; the second explores the possibility that secondary faulting can be due, among other possible geological factors, to the accommodation at surface of strain changes associated with the co-seismically induced curvature of datum surfaces (e.g., Lisle, 1994).

In the following section, we explore these two possible correlations with the case study of the 2009 L'Aquila earthquake, one of the best-documented recent earthquakes worldwide where extensive studies and field survey has been performed on the primary and distributed dislocations.

\section{Co-seismic deformation field and the occurrence of DF during the 2009 L'Aquila Earthquake (Mw 6.3): insights from stress transfer and curvature analysis}

On $06^{\text {th }}$ April 2009, the L'Aquila Earthquake (Mw 6.3) occurred on the Paganica fault (PAG in Figure 3.1) after a long seismic sequence characterized as a seismic swarm. Several field surveys were conducted during the weeks following the main shock to characterize the pattern of surface faulting. Primary faulting, over a length of $6 \mathrm{~km}$ with a maximum surface displacement of $15 \mathrm{~cm}$, was recognized along the Paganica fault. The field surveys also addressed other faults in the area. The results are reported in Figure 3.1 (modified after Guerrieri et al., 2010), where the recorded co-seismic deformation along capable faults (in yellow) superposes the co-seismic InSAR-derived deformation field or interferograms and all the faults shown on the geological map of the area (Geological Cartography [CARG] Project - "L'Aquila" Sheet, scale 1:50,000).

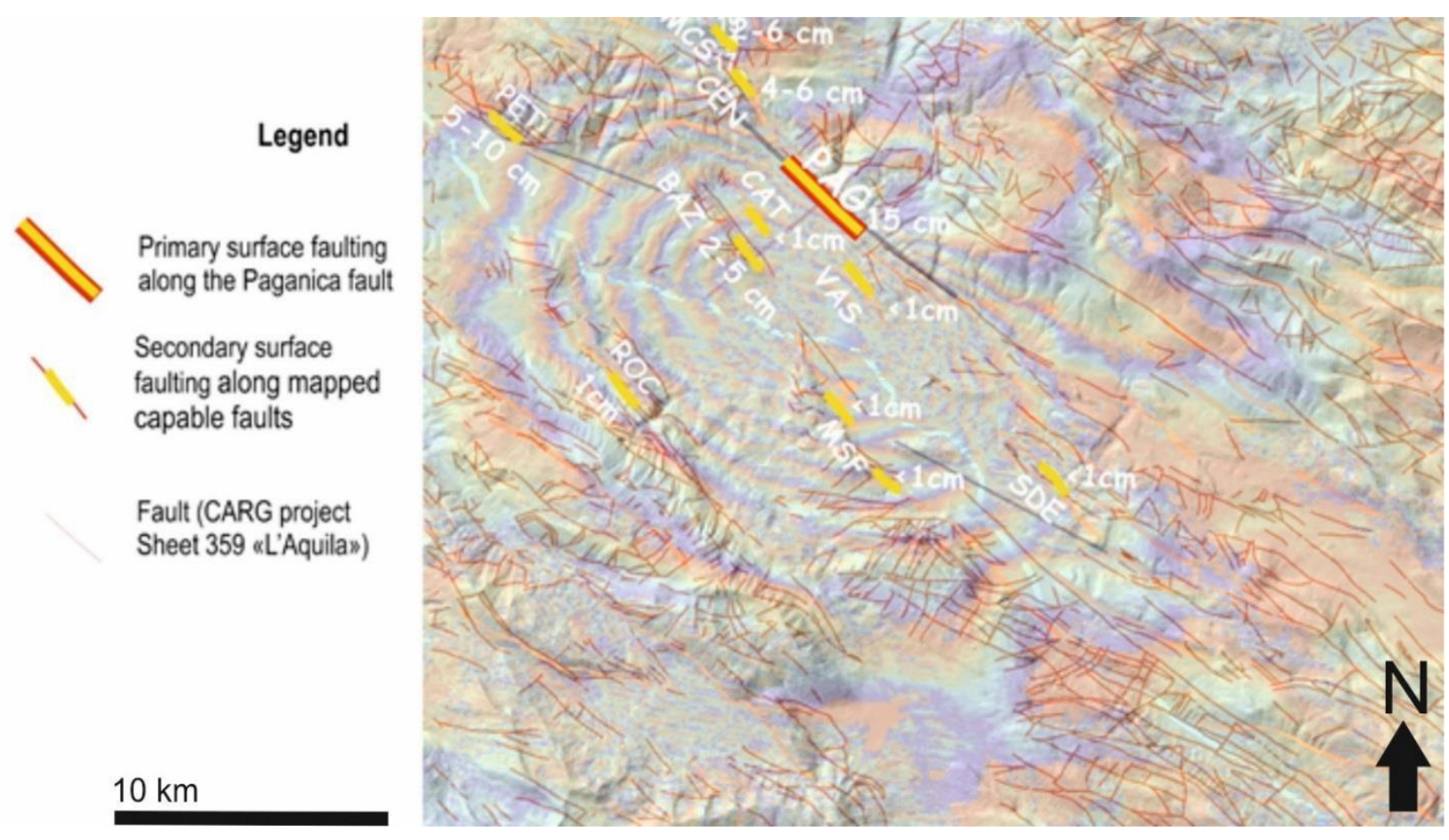

Figure 3.1. Co-seismic reactivation along capable faults induced by the 2009 L'Aquila Earthquake (modified after Guerrieri et al., 2010). Red lines indicate all the mapped faults in the study area at 1:50,000 scale (CARG Project http://www.isprambiente.gov.it/Media/carg/359_LAQUILA/Foglio.html). Labels are BAZ, Bazzano fault; CAT, Colle Caticchio fault; CEN, Colle Enzano fault; MCS, Monte Castellano fault; MSF, Monte San Franco fault; PAG, Paganica fault. 
In particular, according to Guerrieri et al. (2010): "Discontinuous and very local ground ruptures, some tens of meters long, with 15-20 cm offset, were found along the NW-SE trending Pettino fault (PET). Along the Bazzano fault (BAZ; cfr. Figure 3.2a), which is a normal fault antithetic to the Paganica fault, a discontinuous free face (i.e., a narrow band at the base of limestone fault plane, often marked by brown soil, interpreted as an evidence of co-seismic surface reactivation of normal faults) was observed for segments of some hundreds of meters with offsets locally up to 5-6 cm. Fractures in the Ciuffino quarry and in the Bazzano industrial area are located along the NW and SE extension of the Caticchio fault (CAT), a minor structure between the Paganica (PAG) and Bazzano (BAZ) faults."

Also quoting from Guerrieri et al. (2010), "A free face about $1 \mathrm{~cm}$ wide (Figure 3.2c) and at least $1 \mathrm{~km}$ long was found along the $125^{\circ} \mathrm{N}$ trending Canetre fault not far from Roio (ROC). At Poggio di Roio, a fracture in the pavement of the road matches this trend. Two fractures in cultivated fields and some other fractures and free faces have suggested the surface reactivation of the Valle degli Asini fault (VAS), near the San Gregorio village. Field evidence supports the surface reactivation of about $1.3 \mathrm{~km}$ along the Colle Enzano fault segment (CEN), a normal structure located not far from Collebrincioni. Ground ruptures have also been observed that correspond to the San Demetrio fault (SDE). All the above mentioned effects are interpreted as expressions of co-seismic reactivation of other faults."

In summary, in addition to the Paganica fault, several other mapped capable faults moved a certain distance and with a certain displacement during the L'Aquila Earthquake, but as clearly shown in Figure 3.1, other faults are present in the area all of which were not surveyed immediately after the earthquake. Therefore, the possibility that other faults in the area also moved cannot be excluded. Simply considering the surface deformation data recorded by InSAR, it is reasonable to infer that other faults have moved, especially in areas that exhibit high deformation. 

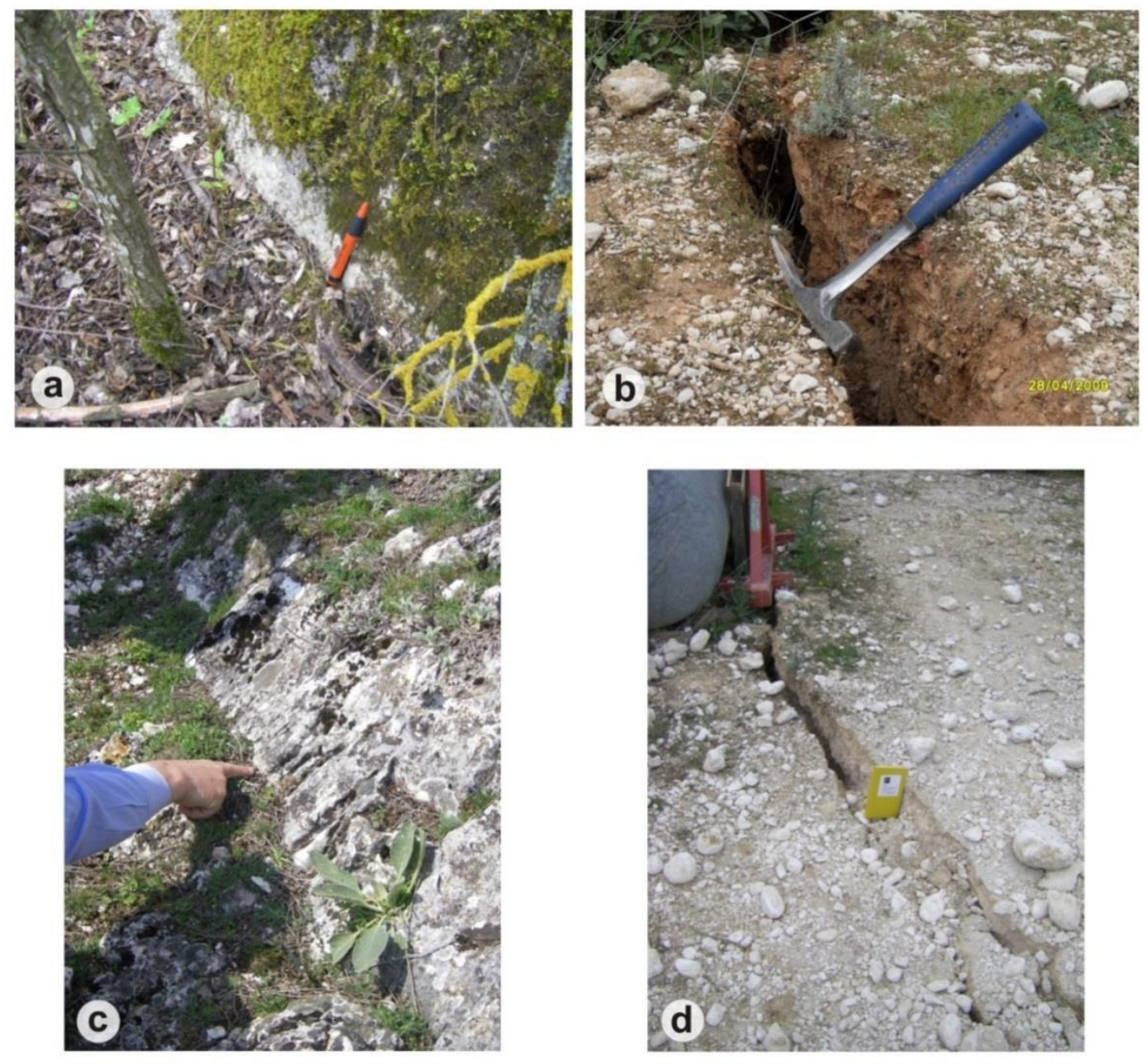

Figure 3.2. Co-seismic reactivations along capable faults: a) BAZ, Fault; b) PAG, fault; c) ROC fault; d) PAG fault.

To explore the link between known DF and surface deformation, we calculated the static (or Coulomb) stress changes induced by the L'Aquila Earthquake on nine faults that experienced offset during the event. Triggering occurs as a result of redistribution of stress induced by an earthquake. Stress in certain regions is actually increased by co-seismic fault slip; if a fault lies in one of these regions, it is predisposed to being triggered. Static stress transfer from source to receiving fault is well constrained by current models, based on elastic half-space dislocation fields (e.g., Okada, 1992). This technique is usually applied to investigate triggering mechanisms of major faults and large earthquakes but could also be applied to investigate secondary faulting distribution.

Calculations were performed in an elastic half-space with uniform isotropic properties using the Coulomb 3.3 code, developed by the United States Geological Survey (Toda et al., 2011). The Paganica fault was considered as the seismogenic source, with the same structural parameters calculated by Walters et al., (2009) based on inversion of the observed InSAR displacement field (Table 3.1). A value of $\mu=0.4$ and a shear modulus of $3.2 \times 10^{10}$ pascals $(\mathrm{Pa})$ were assumed.

Table 3.1

Source parameters for the L'Aquila Earthquake

\begin{tabular}{|l|c|c|c|c|c|c|c|}
\hline & $\begin{array}{c}\text { Strike } \\
(\text { Degrees })\end{array}$ & $\begin{array}{c}\text { Dip } \\
(\text { Degrees })\end{array}$ & $\begin{array}{c}\text { Rake } \\
(\text { Degrees })\end{array}$ & $\begin{array}{c}\text { Slip } \\
(\mathrm{m})\end{array}$ & $\begin{array}{c}\text { Top } \\
(\mathrm{km})\end{array}$ & $\begin{array}{c}\text { Bottom } \\
(\mathrm{km})\end{array}$ & $\begin{array}{c}\text { Magnitude } \\
\text { Mw }\end{array}$ \\
\hline Value & 144 & 54 & -105 & 0.66 & 3 & 11.7 & 6.23 \\
\hline Uncertainty \pm & 1 & 1 & 3 & 0.02 & 0.1 & 0.3 & \\
\hline
\end{tabular}


The location and strike of secondary faults (designated as receiving faults in Coulomb 3.3 software) are calculated using generalized straight segments from the digitized faults shown in Figure 3.1. A dip of 60 degrees, a rake of -90 (pure dip-slip, normal faults), and a down-dip extent of $5 \mathrm{~km}$ is assumed for each fault, based on published geologic cross-sections (Servizio Geologico d'Italia, 2006; Guerrieri et al., 2010; Bonini et al., 2014). Given these parameters, displacement field and Coulomb stress change on each receiving fault are calculated at the surface (zero depth).

Results are summarized in Figure 3.3. Almost all of the secondary faults that were offset during the L'Aquila Earthquake experienced moderate positive changes in Coulomb stress. Only the Colle Caticchio structure, associated with a very limited estimated offset $(<1 \mathrm{~cm})$, shows a negative Coulomb stress change.

a)

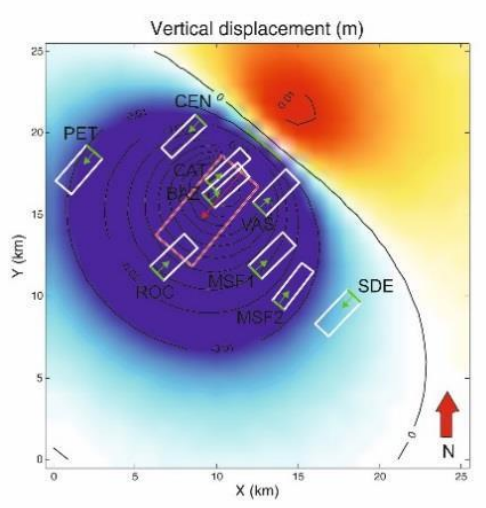

b)

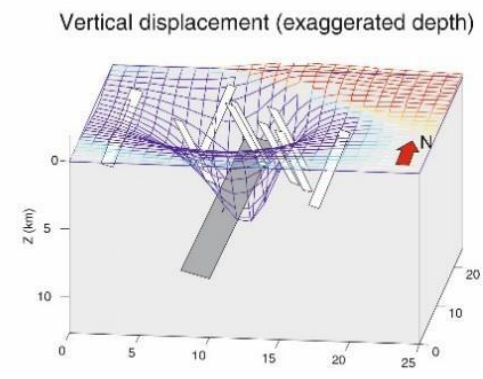

c)

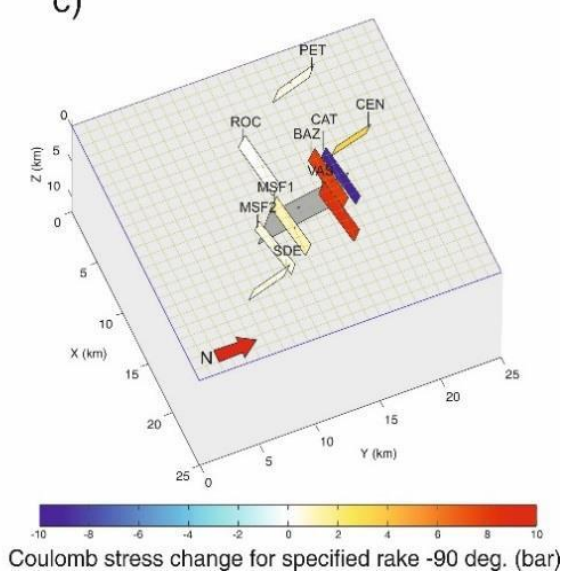

Figure 3.3. Elastic dislocation model and static stress changes caused by the L'Aquila Earthquake, modeled on the Paganica Fault parameters, as derived by Walters et al. (2009); see text for details. Map view and contouring (a) and 3D view (b) of vertical displacement at surface (in meters) and comparison with the distribution of secondary faults that experienced offset during the L'Aquila Earthquake. White boxes in (a) represent the map projection of dipping planes, arrows indicate the dip direction, and the red box indicates the primary Paganica fault. A 3D view of the static stress change induced by the L'Aquila Earthquake on the considered secondary faults is provided in (c); positive stress changes induce the considered fault to slip.

Therefore, we suggest that Coulomb stress transfer can be a valuable tool to assess the likelihood of reactivation of pre-existing faults as DF, given a primary fault movement. Nevertheless, to accurately model fault reactivation, one must have an a-priori knowledge of the geometries of the receiving faults, as well as the primary fault itself. In many cases, such detailed information is lacking, and usually only primary fault geometry is well known. Therefore, to predict the probability of DF, a model based solely on primary fault geometry and slip is needed.

In this study, we consider once again the possibility that DF could preferentially occur in those sectors where greater strain is induced by co-seismic deformation. To explore this potential correlation, in Figure 3.4, the InSAR-derived LOS displacement along a section crosscutting the normal L'Aquila primary fault is plotted against curves for conditional probability of slip on DF (Youngs et al., 2003). The section trace is provided in Figure 2.5. The same graph presents the observed displacements of DF, measured soon after the main shock (the fault codes are reported in Figure 3.1). Finally, the curvature graph of the LOS displacement section was added (i.e. second derivative of the displacement), where negative and positive values indicate downward or upward concave sector of the profile, respectively. We observed that there is a good correlation between slip and the absolute value of curvature; in particular, the highest slip values along the Monte Castellano fault and Colle Enzano fault are located in their respective footwall sectors, where probability curves do not predict a high probability of surface rupture. 


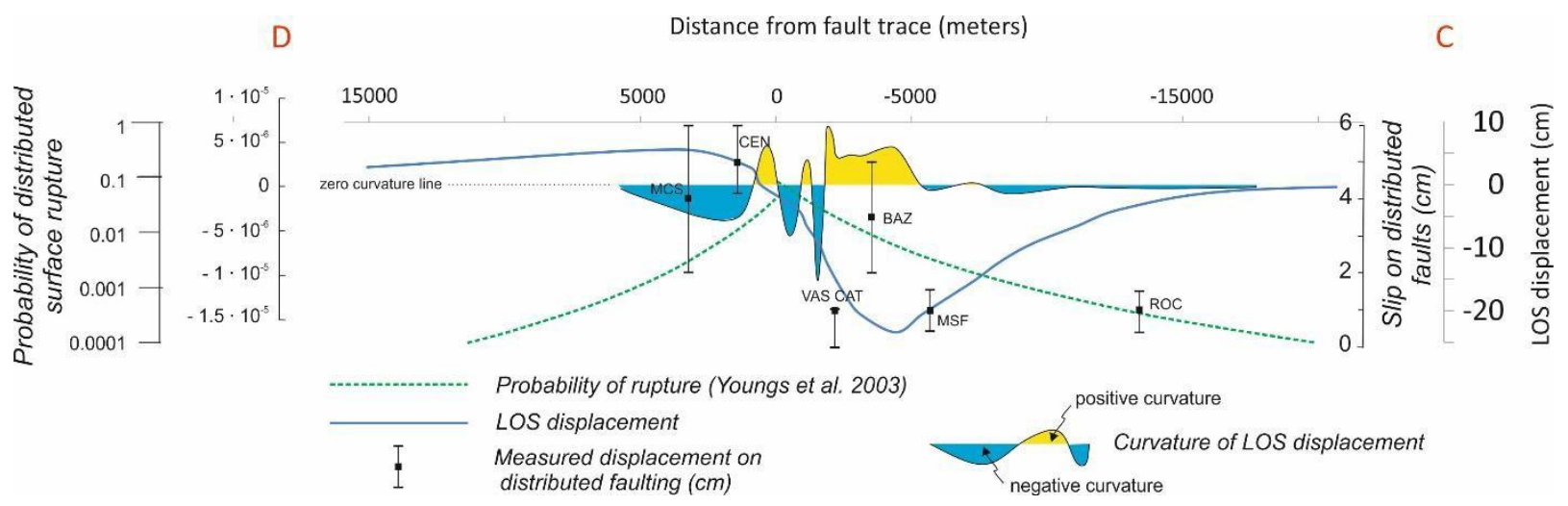

Figure 3.4. InSAR-derived LOS displacements across the area affected by the L'Aquila Earthquake (cfr. Figure 2.5 for section trace) plotted against curves for conditional probability of slip on DF (Youngs et al., 2003) and observed displacements measured soon after the main shock. See the text for further comments.

Summarizing, the L'Aquila earthquake case study suggests that DF occurrence is spatially correlated with co-seismic crustal strain and can be promoted by static stress transfer from the primary fault. We therefore propose that such models have to be incorporated in the present practice of PFDHA, for recognizing areas more prone to DF or, conversely, defining the boundaries of areas less probably subject to DF in case of a strong earthquake. In the following section we propose such an approach, including all the regressions and correlations observed.

\section{Proposed approach for FDHA in NPP siting}

Fault displacement hazard potential has been regarded as one of the substantial exclusionary criteria for assessing the suitability of an NPP site. This criterion first made its way into nuclear regulations through the United States Code of Federal Regulations (CFR) 10 CFR 100, Appendix A (i.e., CFR, 1962). Since then, other language has been used to characterize this hazard. IAEA SSG- 9 (IAEA, 2010) uses "capable fault" to refer to the tectonic feature and "fault displacement hazard" to characterize the potential effect of this feature on NPP structures, systems, and components (SSC).

In IAEA SSG-9, fault displacement hazard is considered part of seismic hazard, and both deterministic and probabilistic approaches are recommended to characterize the hazard. It is worth recalling that the major difference between a probabilistic versus a deterministic approach in the context of seismic hazard analysis is the fact that in a probabilistic approach the recurrence rates of earthquakes are also considered. In fact, the IAEA Safety Guide SSG-9 emphasizes that the two approaches should utilize the same database and also treat the aleatory and epistemic uncertainties in a similar manner in a PSHA and a DSHA. The recurrence rates that are considered in a PSHA require the definition of a time frame. This is generally done using the historical seismicity data with the application of completeness corrections and truncating the curve at some Mmax which is generally based on the tectonic capability of the causative structures.

For the definition of capable faults, there has always been an underlying consideration of a probabilistic approach (even though never explicitly stated) because of the time element involved. In fact, the issue of fault capability is clearly tied to the age of the fault's most recent and/or recurrent movement. More specifically, the age range used to determine capability is linked to the seismotectonic context in which it is located. In recent project experience, time intervals going from several tens of thousands of years (North Anatolia fault zone) to 1 million years, in the case of Bangka Island in Indonesia, have been considered.

We can interpret these time intervals as the extreme points of a scale that ranges from highly active areas like plate boundaries (e.g. California, Japan, African Rift) and huge and well known transform and graben zones (e.g. Dead Sea fault zone, North Anatolia fault zone, Rhine Rift System) to cratonic areas significantly far away from subduction zones like Russia-Siberia, Eastern US, UK or part of eastern Europe.

Elements that need to be considered when assuming the appropriate time frame for a fault potentially assessed to be capable are mainly related to the plate motion and the rheological characteristic of the crust and to other important elements such as e.g., isostatic glacial rebound (e.g., Lundqvist \& Lagerbäck, 1976) and induced seismicity (The National Academic Press, 2013) as well.

Taking into consideration IAEA SSG-9, the following procedure (Figure 4.1), which consists of three major steps, is proposed to address fault displacement issues at NPP sites and including the zoning of areas more prone to DF, as proposed above. 
1a - Identification of the major seismogenic structures within the Site Region sensu IAEA (2010)

$\downarrow$

$1 \mathrm{~b}$ - Definition of the Maximum expected earthquake on these structures and of the time interval for fault capability assessment

1c - Overlay of the areas expected to be deformed by each of the considered seismogenic structures assuming the Maximum expected earthquake. Comparison with faults in the Site Vicinity sensu IAEA (2010)
STEP 1 - Assessing fault capability
$1 \mathrm{~d} 1$ - Site vicinity faults are $1 \mathrm{~d} 2$ - Site vicinity faults are not covered by deformed areas from 1c - same time frame for fault capability assessment as fault capability assessment has

$$
\text { in 1c. }
$$

covered by deformed areas from $1 \mathrm{c}$ - the time frame for to be defined according to seismotectonic setting b1 -

Capable

Fault in

the plant

area

\section{2b2 - Capable Fault}

in the Site Vicinity

but not in the plant area

2c - Evaluation of the probability to affect the NPP

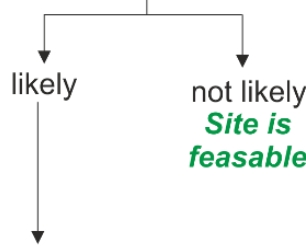

3a - Estimate a lower bound

for fault displacement (i.e.,

$$
\text { a few centimeters) }
$$

$3 b-$ Calcul annual frequency of exceedance on the

$$
\text { fault }
$$$$
\checkmark
$$

$3 c$ - Calculate the annual frequency of exceedance of displacement at the NPP $(\mathrm{Pd})$

(e.g., Finite element analysis,

elastic halfspace dislocation models)

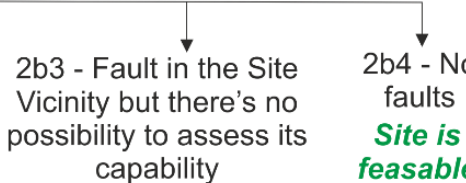
capability

\section{$2 d$ - Evaluation of the} possibility that the

fault can be reactivated by the seismogenic structures or other capable faults (i.e. Coulomb stress transfer, curvature analysis etc.)

fault cannot likely be activate

- likely be reactivated Site is feasable

STEP 3 - evaluating the expected surface displacement and its probability of occurrence
STEP 2 - evaluating the singificance of surface displacement

Figure 4.1. Proposed workflow for the assessment of primary and distributed fault displacement hazard in the case of NPP. 


\section{Step 1 - Assessing fault capability.}

Determine fault capability according to the definition given by IAEA SSG-9 (The definitions given by the USNRC and the NRA are also consistent with the IAEA SSG-9 definition). A major obstacle is the definition of the appropriate time interval that has to be considered in order to assess the capability of faults located in the Site Vicinity (i.e., minimum $5 \mathrm{~km}$ radius around the site, IAEA, 2010). This strongly relies on the seismotectonic characteristics of the region where the fault under investigation is located. We propose that the major seismogenic structures in the NPP Site Region (sensu IAEA, 2010), have to be considered first (1a on Figure 4.1). These structures have to be characterized (1b) in terms of Maximum expected earthquake and time interval for the assessment of activity, as discussed above. Assuming that these structures can induce significant deformation of surrounding areas during major earthquakes, and considering that significant stress can be transferred on surrounding faults, we then propose a GIS-based buffer approach, in order to identify all the surrounding faults, located in the Site Vicinity area, possibly influenced by such a deformation field. The key question is here the possible presence of capable faults, primary or distributed, within the Site Vicinity area that would be a possible source of effects on the NPP plant area.

First, considering the Maximum expected earthquake on a major seismogenic structure, estimate the size of the area significantly deformed by co-seismic slip (Figure 2.10). Overlay the estimated deformed area on the Site Vicinity area to identify all faults possibly influenced by this deformation and stress perturbation (1c). We propose that: a) if a site vicinity fault is covered by buffered areas (1d1), the same time interval to assess fault capability has to be applied both for the major seismogenic structure and the fault itself; b) if a site vicinity fault is not covered by buffered areas (1d2), a new time interval has to be assessed for this fault, according to e.g., regional seismotectonic setting, crustal or overall lithospheric characteristics, subduction type and geometry, isostasy due to loading or unloading (e.g., glacial rebound or forebulge), induced seismicity, and volcanism (e.g. Gurpinar and Serva, 2015).

\section{Step 2 - Evaluating the significance of surface displacement.}

In this step we do not consider the initiation of new faults (primary or distributed) as a possible scenario, implying that over the future time interval considered by PFDHA such an occurrence is highly improbable. Conversely, only re-activation of pre-existing faults will be taken into account.

If there is at least one primary or secondary capable, or potentially capable, fault within the site vicinity, including the site area and possibly under the NPP itself, it is important to first determine whether or not the fault could potentially approach and subsequently cause surface displacement under the NPP safety-related SSCs.

If a capable fault is actually under the site (2b1), then Step 3 applies. However, if a capable (2bs) or potentially capable (2b3) fault is in the site vicinity and several kilometers away from NPP SSCs, then a decision must be made regarding the fault's potential for affecting safety-related SSCs, based on the fault's characteristics, such as its length, geometry (including strike and dip; orientation) and structural relationship with the causative fault. We propose to use well-accepted models such as half-space elastic dislocation models, (e.g., Okada, 1985, 1992; Cohen, 1999) to estimate earthquake-induced surface deformation predicted for slip distribution at depth, given fault geometry and slip. The deformation fields predicted by these models can be used a) to model static stress transfer on pre-existing faults, if detailed, local geologic fault data are available, or b) as a first proxy to locate areas more prone to DF in the case a major earthquake occurs along a well-known, primary fault. In fact, the L'Aquila Earthquake case study shows a clear, positive correlation between the absolute value of curvature of the earthquake-induced surface deformation and slip on DF (i.e. Figure 3.4).

We acknowledge that crustal deformation is not solely linked to faulting and that it is also necessary to consider crustal rheology. Nevertheless, rheology does not necessarily change significantly at the scale of investigation (i.e., within a few tens of kilometers and thickness of affected crust) and, therefore, it can be assumed to be constant. On the other hand, rock mechanical properties (i.e., Poisson's ratio and Young's modulus) could differ in the upper part of the crust according to factors such as lithology, depth of weathering or the degree of rock mass fracturing.

Faulting in a deformed area results from crust rheology and the mechanical properties of the rocks located therein. Moreover, the results of the L'Aquila Earthquake case study, assuming typical values of these parameters from published data, fit well with observed DF data, which in this case demonstrates the relative insensitivity of the model to the possible range of these parameters. Moreover, it is important to note that over the long term (geologic time interval); faults whose attitude is compatible with the present stress regime and that are located in the deformed area are likely to move. Over the short term (engineering time interval), it may be necessary to consider the probability that new, secondary faults could be generated. Although we believe that this probability is close to zero over this time range, one must at least consider the possibility of secondary faulting due to localized strain partitioning, e.g., stepover Reidel shears and tear faults. Outcomes of this analysis can be a 
classification of mapped faults as prone or not prone to be re-activated or a zonation of the site vicinity area basing on curvature analysis. If necessary, this evaluation could also be performed probabilistically, and a logic tree may be constructed to assess the potential of the fault to cause a safety issue.

\section{Step 3 - Evaluating the expected surface displacement and its probability of occurrence.}

If at least one fault has the potential to cause a displacement hazard to NPP safety-related SSCs, this step should be implemented and it is clearly probabilistic, as the decision related to safety impacts must involve readily quantifiable plant safety metrics.

The following procedure is proposed for each fault that could compromise NPP safety:

- Using engineering methods and judgment, estimate a conservative lower-bound fault displacement amplitude under the plant for which there will be no safety impact on NPP structures, given the foundation basemat dimensions and soil conditions. In the absence of regulatory criteria, expert consensus on this value is essential. Conservatively, this value is estimated to range from $5 \mathrm{~cm}$ to $10 \mathrm{~cm}$, depending on soil condition and foundation design. Calculate the annual frequency of exceedance of displacements that can occur at the main causative fault, using methods available in the literature.

- Calculate the annual frequency of exceedance of displacements that can occur at the foundation of each NPP structure, using published data, empirical relationships, and engineering models (such as Finite Element Analysis or Coulomb static stress transfer models) compatible with the faulting type and site area geologic conditions. Note that this step is necessary if the fault under the NPP foundation is expected only to move co- seismically with the causative fault.

- Assume a threshold value of approximately $1 \%$ of the core damage frequency (CDF), calculated from a recent probabilistic safety analysis of the NPP. This could be approximately $10^{-7}$, i.e., approximately 1 $\%$ of the CDF. Such a value can be considered to be a screening value.

- If the displacement corresponding to the small pre-selected value occurs with a frequency less than the screening value, then this hazard will not be significant for the NPP because at worst, it will contribute 1 percent to $\mathrm{CDF}$, even if it is postulated as a singleton to core damage (i.e., its occurrence will directly result in core damage).

It should be noted that the numerical parameters presented above must be decided on a case-by- case basis and in compliance with national and international regulatory requirements.

\section{Discussion}

The data reported above brings into question the proximity issue of the co-seismic deformation field and the probability curves derived from available field data. In particular, both InSAR and detailed field survey data (e.g., the L'Aquila earthquake case study), suggest that DF may occur in the area proximal to the main fault trace, in the relatively far-field region. This would indicate that available datasets on faulting, derived from field surveys conducted soon after a major earthquake, could be significantly incomplete or biased by field survey planning, which usually focuses on major, well-known faults, particularly those near to a site. Likewise, it should be noted that the analyses discussed in this paper does not take into account the possibility of post-event slip (i.e. after slip) or aftershock slip - a refinement that should be considered in future research efforts.

The possibility that datasets are incomplete or biased is even more significant for DF, because it has never been standard practice to check a representative sample of the mapped faults in a deformed area. Although these data are highly valuable, they do not reflect the real spatial patterns of faulting, especially with respect to DF. Consequently, attempts to ascertain the spatial extent of DF may result in gross approximation or oversimplification, and possibly an underestimate of the true distribution of faulting after a major earthquake. Practically speaking, all observed and studied deformations have occurred on pre-existing faults. This is to be expected, as the long tectonic history of almost all geologic terrains, especially in highly active areas, causes the uppermost part of the crust to be highly dissected by discontinuities which often attract the most attention. It appears that characterization of the whole near-surface crustal deformation is a more effective and accurate tool for predicting the spatial distribution of faulting than calculation of a simple distance relationship, which is currently the state of the practice in the industry.

As indicated in the previous section, the crustal deformation fields that result from large earthquake may cause co-seismic or post-seismic fault displacement on secondary tectonic structures. Furthermore, the patterns of strain may contribute to significant variations in VGM within a small area, a phenomenon that is difficult to explain using currently available GMPEs and conventional site-effect parameters.

One issue that has not attracted much attention is the potential effects of site vicinity tectonism on VGM at an NPP site, and more specifically, at each NPP unit, if the site has multiple units. This 
possibility lies within the realm of so-called "near-field site effects," which may include many different considerations. Site effects may be caused by a variety of phenomena, such as a) frequency shifts due to linear or nonlinear soil responses, b) focusing due to topography, c) inhomogeneities and non- horizontal layering, d) ground motion directivity, e) change in boundary conditions, and f) co-seismic movement of secondary tectonic features.

The last item is generally not integrated into GMPEs, and it is not considered in site response analysis. It is very rare that sufficient data exist for both recorded ground motion and for local tectonism (with the potential for co-seismic movement) in a small area corresponding to the near-field region for NPPs.

Figure 2.10 shows the areas affected by surface deformation during recent earthquakes. In the majority of cases, nearby seismic sources contribute significantly to the seismic hazard of NPPs. For example, if it is assumed that the de-aggregation of seismic hazard indicates a seismic source of Mw 6 to Mw 6.5 is located nearby - at a distance of approximately $15 \mathrm{~km}$ to $20 \mathrm{~km}$ - an area of approximately 1,000 square kilometers will experience appreciable surface deformation as indicated in Figure 2.1. This is an area on the order of the size of the near region (IAEA, 2010). Consequently, it is likely that tectonic structures will be in the near-field around the NPP that may move co-seismically with the causative fault. How this would affect ground motion at the site has not been studied sufficiently, and in general, this factor is not taken into account in seismic hazard analysis.

Below, we report one example that may provide evidence that the co-seismic motion of secondary tectonic structures may have played a role in differences in recorded ground motion: the Kashiwazaki-Kariwa records of the Niigataken Chuetsu-oki Earthquake in 2007.

The observed accelerations at the foundation base mats of the seven different units were such that TEPCO eventually decided to adjust the new "peak value of the design basis seismic motion for SSCs (on the free surface of the base stratum" more than $2 \mathrm{~g}$ for Unit 1 through Unit 4 and more than $1 \mathrm{~g}$ for Unit 5 through Unit 7 (a factor of 2 between the south versus the north part of the site).

The calculations based on fault simulation also confirmed this significant difference. It should be noted that the distance between Unit 1 to Unit 4 and Unit 5 to Unit 7 is only approximately $1 \mathrm{~km}$. At least part of this increase may be due to the presence of the Madonosaka syncline near the southern units. It is difficult to attribute the difference to any of the conventional site effects. In fact, an IAEA project, Kashiwazaki-Kariwa Research Initiative for Seismic Margin Assessment (KARISMA), in which international institutes participated, attempted to establish the reasons for the difference but without much success (IAEA, 2013).

The second example involves the Great Tohoku Earthquake of 2011 and the records obtained from the Fukushima Daiichi and Fukushima Daini NPPs, which are located approximately $200 \mathrm{~km}$ from the epicenter and approximately $10 \mathrm{~km}$ apart.

Table 5.1

Observed peak accelerations at base mat slab of reactor building at Fukushima Daiichi NPP

\begin{tabular}{c|c|c|c}
\hline & $\begin{array}{c}\text { Observed } \\
\text { PGA N-S (Gal) }\end{array}$ & $\begin{array}{c}\text { Observed } \\
\text { PGA E-W }(\text { Gal })\end{array}$ & $\begin{array}{c}\text { Observed } \\
\text { PGA U-D (Gal) }\end{array}$ \\
\hline Unit 1 & 460 & 447 & 258 \\
\hline Unit 2 & 348 & 550 & 302 \\
\hline Unit 3 & 322 & 507 & 231 \\
\hline Unit 4 & 281 & 319 & 200 \\
\hline Unit 5 & 311 & 548 & 256 \\
\hline Unit 6 & 298 & 444 & 244 \\
\hline Average & 337 & 469 & 249 \\
\hline
\end{tabular}

Table 5.2

Observed peak accelerations at base mat slab of reactor building at Fukushima Daini NPP

\begin{tabular}{c|c|c|c}
\hline & $\begin{array}{c}\text { Observed } \\
\text { PGA N-S }(\text { Gal })\end{array}$ & $\begin{array}{c}\text { Observed } \\
\text { PGA E-W }(\text { Gal })\end{array}$ & $\begin{array}{c}\text { Observed } \\
\text { PGA U-D }(\text { Gal })\end{array}$ \\
\hline Unit 1 & 254 & 230 & 305 \\
\hline Unit 2 & 243 & 196 & 232 \\
\hline Unit 3 & 277 & 216 & 208 \\
\hline
\end{tabular}




\begin{tabular}{c|c|c|c}
\hline Unit 4 & 210 & 205 & 288 \\
\hline Average & 246 & 212 & 258 \\
\hline
\end{tabular}

For approximately the same distance from epicenter and distance from fault rupture (approximately $200 \mathrm{~km})$, the base mat motions at the two plants differ significantly. The soil properties are similar ( 50 $\mathrm{m}$ to shear-wave velocity $[\mathrm{Vs}]=700$ - kilometer-per-second $[\mathrm{km} / \mathrm{s}]$ layer). Plant structures are also similar, and the embedment depth $\sim 10 \mathrm{~m}$ to $12 \mathrm{~m}$ for all units. Based on the data from Table 5.1 and Table 5.2, the following calculation can be performed (Table 5.3).

Table 5.3

Derived parameters on the recorded ground accelerations listed in Table 5.1 and 5.2.

\begin{tabular}{|c|c|c|c|c|c|}
\hline \multirow{2}{*}{ Site } & \multirow{2}{*}{ NS/EW } & \multirow{2}{*}{ UD } & \multicolumn{3}{|c|}{ Daiichi Average/Daini Average } \\
\hline & & & NS & EW & UD \\
\hline Daiichi & 0.78 & $\begin{array}{c}\text { Lowest } \\
\text { Component }\end{array}$ & \multirow[b]{2}{*}{1.49} & \multirow[b]{2}{*}{2.21} & \multirow[b]{2}{*}{0.97} \\
\hline Daini & 1.16 & $\begin{array}{c}\text { Highest } \\
\text { Component }\end{array}$ & & & \\
\hline
\end{tabular}

Unfortunately, due to the lack of detailed data on local tectonism near the two sites, it is not possible to attribute the difference to any one phenomenon. It is clear, however, that available GMPEs and site response analysis methods are insufficient to explain such differences in ground motion.

\section{Conclusions}

Based on the findings of this study, the following conclusions are drawn:

- The shortcomings of the present database must be recognized in PFDHA as they represent additional sources of uncertainties and oversimplify processes that should be considered.

- Post-earthquake field investigations should consider faults in the deformed area to support the database for future PFDHA. InSAR and other remote-sensing data (e.g. change detection from LiDAR) obtained from similar events may provide useful guidance for investigation of the deformed area.

- If an NPP site is within the deformed area of the maximum potential earthquake that occurs on a seismogenic structure, there are two major implications:

- The time frame for capability (as per IAEA, 2010) can be established based on this finding.

- Increased scrutiny is needed for the faults within the deformed area, and appropriate assumptions must be made when uncertainties cannot be eliminated. Faults that have sympathetic attributes relative to the main seismogenic structure are more likely to move co-seismically.

- Fault capability and fault displacement hazard in relation to NPPs must be considered quantitatively and within the framework of probabilistic nuclear safety targets. In general, regulatory guidance is lacking in this area.

- Significant VGM variation may occur due to local tectonism that has caused co-seismic deformation. This is difficult to observe due to the lack of strong-motion data as well as fault-related data. However, when such data are available, differences have been observed that cannot be explained using GMPEs or site response analysis. Further work is needed on this subject, including assessment of aleatory uncertainty of the deformation.

\section{Acknowledgments}

We want to thank Dr. Fiorenzo Fumanti, Dr. Luca Guerrieri, Dr. M. Logan Cline, and Ms. Susan Bertone for fruitful discussions and the significant work they performed in the preparation of the figures and text for this manuscript. We want also to thank Dr. Makoto Takao for his valuable comments. 


\section{Bibliography}

\section{References}

ANSI/ANS-2.30, 2015. Criteria for Assessing Tectonic Surface Fault Rupture and Deformation at Nuclear Facilities. Published by the American Nuclear Society.

Baize, S., Scotti, O., 2015. The Napa Earthquake, California (M=6; 24/08/2014). Post-seismic survey report, with special focus on surface faulting. IRSN technical report.

Bonini, L., Di Bucci, D., Toscani, G., Seno, S., Valensise, G., 2014. On the complexity of surface ruptures during normal faulting earthquakes: excerpts from the 6 April 2009 L'Aquila (central Italy) Earthquake (Mw 6.3), Solid Earth, 5(1), 389-408.

Cakir, Z., Meghraoui, M., Akoglu, A. M., Jabour, N., Belabbes, S., Ait-Brahim, L., 2006. Surface deformation associated with the Mw 6.4, 24 February 2004 Al Hoceima, Morocco, earthquake deduced from InSAR: implications for the active tectonics along North Africa, Bulletin of the Seismological Society of America, 96(1), 59-68.

CFR, 1962. 10 CFR 100 Appendix A. Reactor Site Criteria. Seismic and Geologic Siting Criteria for Nuclear Power Plants. Code of Federal Regulations, Washington, D.C., USA.

Cohen, S. C., 1999. Numerical models of crustal deformation in seismic zones. Advances in Geophysics, 41, 133-232.

Fialko, Y., Sandwell, D., Agnew, D., Simons, M., Shearer, P., Minster, B., 2002. Deformation on nearby faults induced by the 1999 Hector Mine earthquake. Science, 297(5588), 1858- 1862. Guerrieri, L., Baer, G., Hamiel, Y., Amit, R., Blumetti, A. M., Comerci, V., Di Manna, P., Michetti, A. M., Salamon, A., Mushkin, A., Sileo, G., Vittori, E., 2010. InSAR data as a field guide for mapping minor earthquake surface ruptures: ground displacements along the Paganica Fault during the 6 April 2009 L'Aquila Earthquake, Journal of Geophysical Research, 115, doi:10.1029/2010JB007579.

Gürpınar, A., Serva, L., 2015. A risk informed engineering approach to consider faults near a NPP. Transactions, SMiRT-23, Manchester, United Kingdom. August 10-14, 2015.

IAEA, 2008. Mission report-engineering safety review services - seismic safety expert mission - 2nd followup- IAEA mission in relation to the findings and lessons learned from the 16 July 2007 earthquake at Kashiwasaki-Kariwa NPP, "The Niigataken Chuetsu-oki Earthquake." Tokyo and KashiwazakiKariwa NPP, Japan. 1-5 December 2008.

IAEA, 2010. IAEA Safety Standards Series No. SSG-9. Seismic Hazards in Site Evaluation for Nuclear Installations. Specific Safety Guide. International Atomic Energy Agency, Vienna.

IAEA, 2013. Review of seismic evaluation methodologies for nuclear power plants based on a benchmark exercise. IAEA-TECDOC series, ISSN 1011- 4289; no. 1722. International Atomic Energy Agency, Vienna.

Livio, F., Serva, L., Gürpinar A., 2016 Locating distributed faulting: Contributions from InSAR imaging to Probabilistic Fault Displacement Hazard Analysis (PFDHA), Quaternary International (2016), http://dx.doi.org/10.1016/j.quaint.2016.09.034.

Lundqvist, J., Lagerbäck, R., 1976. The Pärve Fault. A late-glacial fault in the Precambrian of Swedish Lapland. Geologiska Föreningen i Stockholm Förhandlingar. Volume 98, Issue 1.

King, G.C.P., Stein, R.S., Lin, J., 1994. Static stress changes and the triggering of earthquakes. Bull. Seismol. Soc. Am. 84, 935 - 953.

Moss, R. E. S., Ross, Z. E., 2011. Probabilistic fault displacement hazard analysis for reverse faults. Bulletin of the Seismological Society of America, 101(4), 1542-1553.

The National Academy Press, 2013. Induced Seismicity Potential in Energy Technologies. Paperback. Washington DC, USA. ISBN: 978-0-309-25367-3

Nishimura, T., Tobita, M., Yarai, H., Ozawa, S., Murakami, M., Yutsudo, T., Ishimoto, M., Umesawa, T., Toyofuku, T., Kawamoto, S., Amagai, T., Fujiwara, M., Suzuki, A., Enya, S., Sasaki, T., Yokokawa, M., Oomori, S., Tanoue, S., Ikeda, H., Nemoto, M., Suito, H., Hayashi, F., Une, H., Koarai, M., Tsuzawa, M., 2008. Crustal deformation and a preliminary fault model of the 2007 Chuetsu-oki earthquake observed by GPS, InSAR, and leveling. Earth, Planets and Space, 60(11), 1093-1098.

Okada, Y., 1985. Surface deformation due to shear and tensile faults in a half-space. Bulletin of the Seismological Society of America, 75(4), 1135-1154.

Okada, Y., 1992. Internal deformation due to shear and tensile faults in a half-space. Bulletin of the Seismological Society of America, 82(2), 1018-1040.

Pathier, E., Fielding, E. J., Wright, T. J., Walker, R., Parsons, B. E., Hensley, S., 2006. Displacement field and 
slip distribution of the 2005 Kashmir earthquake from SAR imagery. Geophysical Research Letters, 33(20).

Petersen, M. D., Dawson, T. E., Chen, R., Cao, T., Wills, C. J., Schwartz, D. P., Frankel, A.D., $\quad 2011 . \quad$ Fault displacement hazard for strike-slip faults. Bulletin of the Seismological Society of America, 101(2), 805-825.

Quittmeyer, R.C., Bavec, M., Riznar, I., Fatehi, A., Blanco Beltran, J., and Rizzo, P.C., Probabilistic $\quad$ Fault Displacement Hazard Analysis for Regulatory Decision-Making: A Case-Study for Krško, Slovenia Submitted to Pure and Applied Geophysics, Topical Volume on Best Practices in Seismic Hazard Analysis for Nuclear Installations

Research Group for Active Faults of Japan, 1991. Active Faults in Japan: sheet maps and inventories (Revised ed.), 437 pp., University of Tokyo Press, Tokyo (in Japanese).

Serva, L., 1995. Criteri geologici per la valutazione della sismicità: considerazioni e proposte, Atti Convegni Lincei, 122. Roma.

Serva, L., Vittori E., Comerci V., Esposito E., Guerrieri L., Michetti A.M., Mohammadioun B., Mohammadioun G., Porfido S., Tatevossian R., 2016. Earthquake Hazard and the Environmental Seismic Intensity (ESI) Scale. Pure Appl. Geophys. 1, 2015, Springer, Basel. DOI 10.1007/s00024-015-1177-8.

Servizio Geologico d'Italia, 2006. Carta Geologica d'Italia alla scala 1:50.000. Foglio n. 359 "L'Aquila". S.EL.CA. Firenze.

Stein, R.S., 1999. The role of stress transfer in earthquake occurrence. Nature, 402(6762), 605-609. Takao, M., Annaka T., Kurita, T., 2013. Application of Probabilistic Fault Displacement Hazard Analysis in Japan. Journal of Japan Association for Earthquake Engineering, 13(1), 17-36.

Toda, S., Stein, R. S., Lin, J., Sevilgen, K., 2011. Coulomb 3.3 user guide.

USNRC Regulatory Guide 1.165, 1997. Identification and characterization of seismic sources and determination of Safe Shutdown earthquake ground motion. US Nuclear Regulatory Commission.

USNRC Regulatory Guide 1.208, 2007. A performance based approach to define the site-specific earthquake ground motion. US Nuclear Regulatory Commission.

Youngs, R. R., Arabasz, W. J., Anderson, R. E., Ramelli, A. E., Ake, J. P., Slemmons, D. B., McCalpin, J. P., Doser, D. I., Fridrich, C. J., Swan III, F. H., Rogers, A. M., Yount, J. C., Anderson, L. W., Smith, K. D., Bruhn, R. L., Knuepfer, L. K., Smith, R. B., dePolo, C.M., O’Leary, K. W., Coppersmith, K. J., Pezzopane, S. K., Schwartz, D. P., Whitney, J.W., Olig, S. S., Toro, G.R., 2003. A methodology for probabilistic fault displacement hazard analysis (PFDHA). Earth Spectra, 19, 191-219.

Walters, R. J., Elliott, J. R., D'Agostino, N., England, P. C., Hunstad, I., Jackson, J. A., Parsons, B., Phillips, R. J., Roberts, G., 2009. The 2009 L'Aquila earthquake (central Italy): A source mechanism and implications for seismic hazard. Geophysical Research Letters, 36(17). 
Click here to download high resolution image

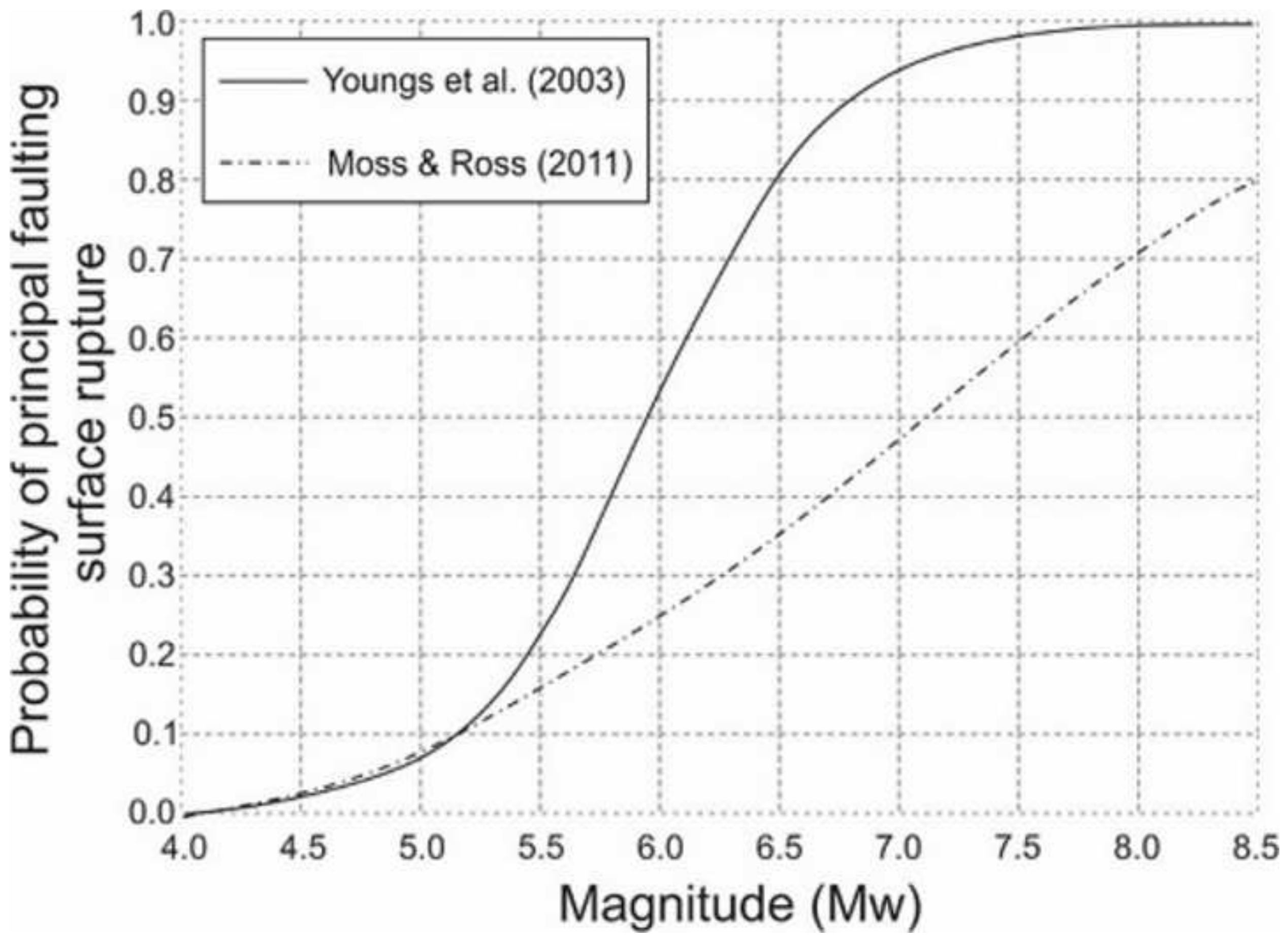


a)

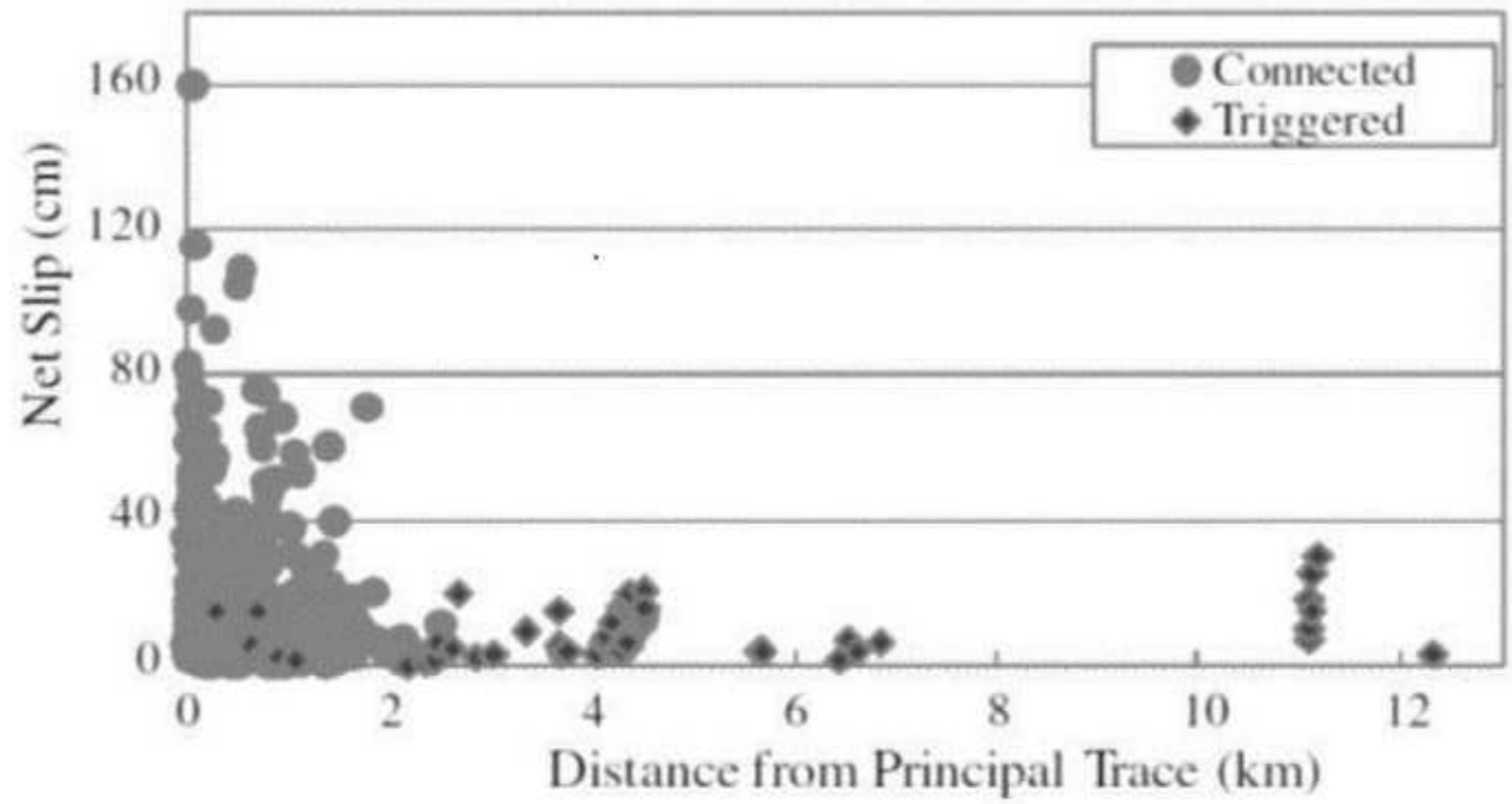


b)

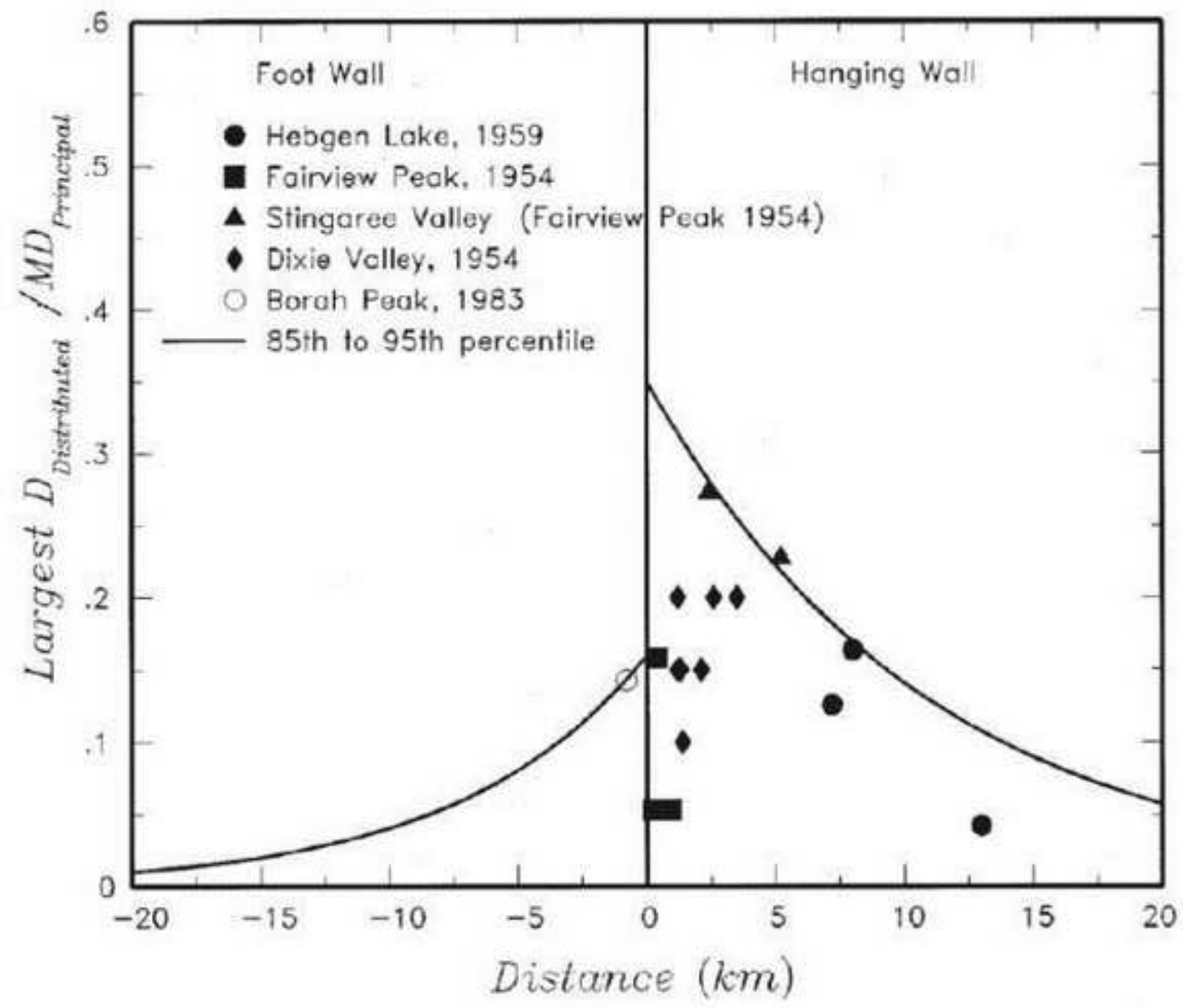


a)
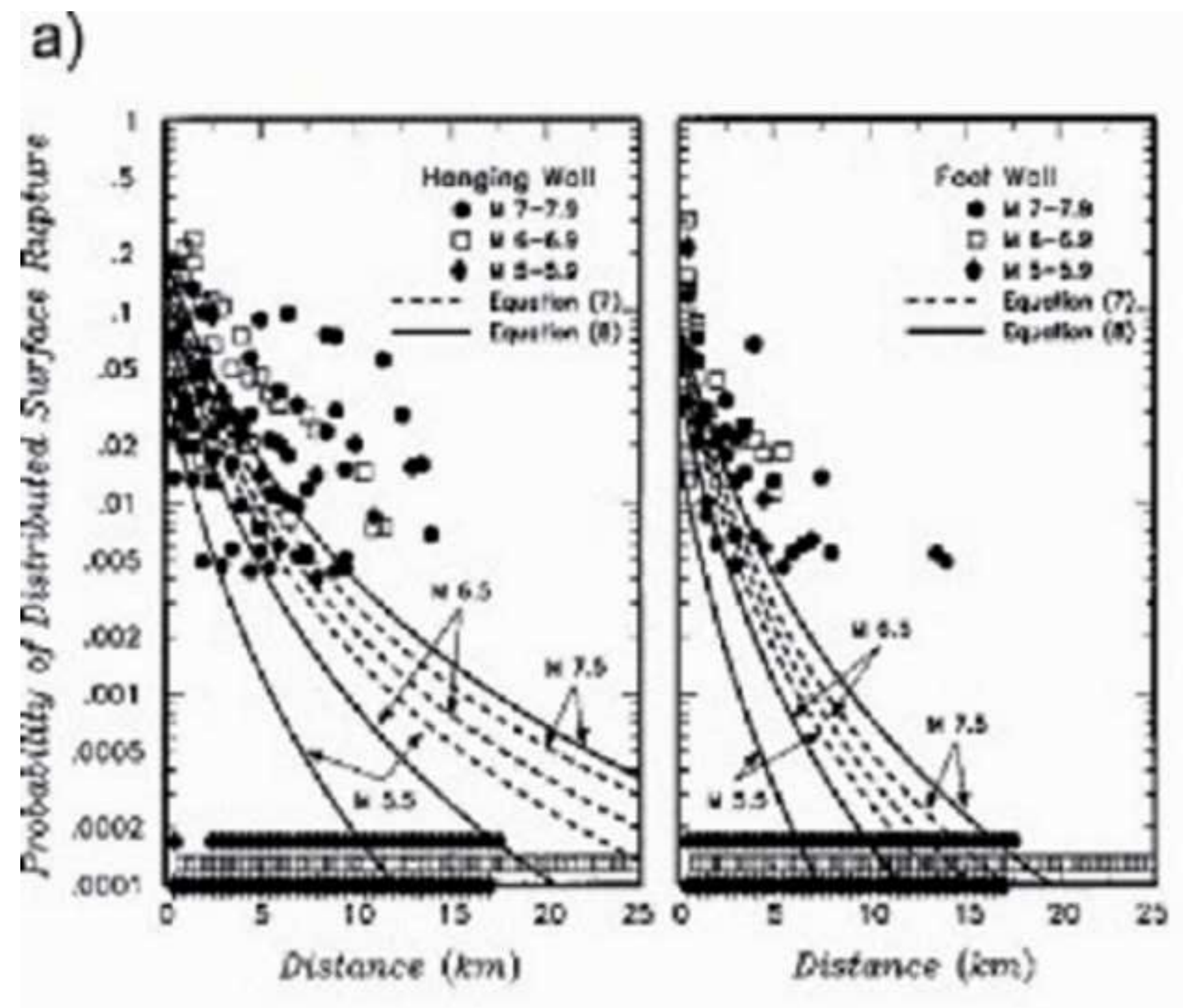

Figure 2.3a) 
Click here to download high resolution image

b)

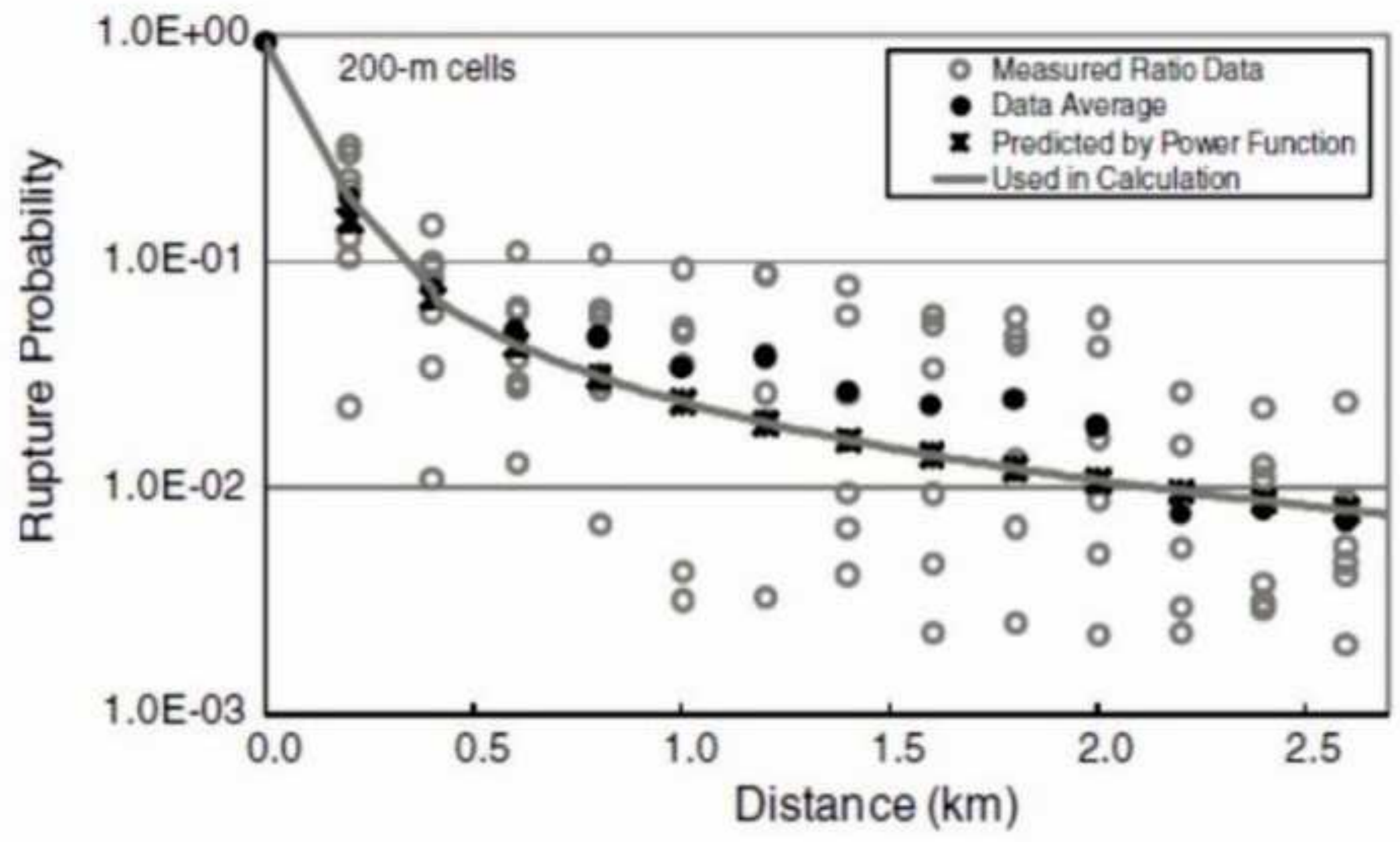


Click here to download high resolution image

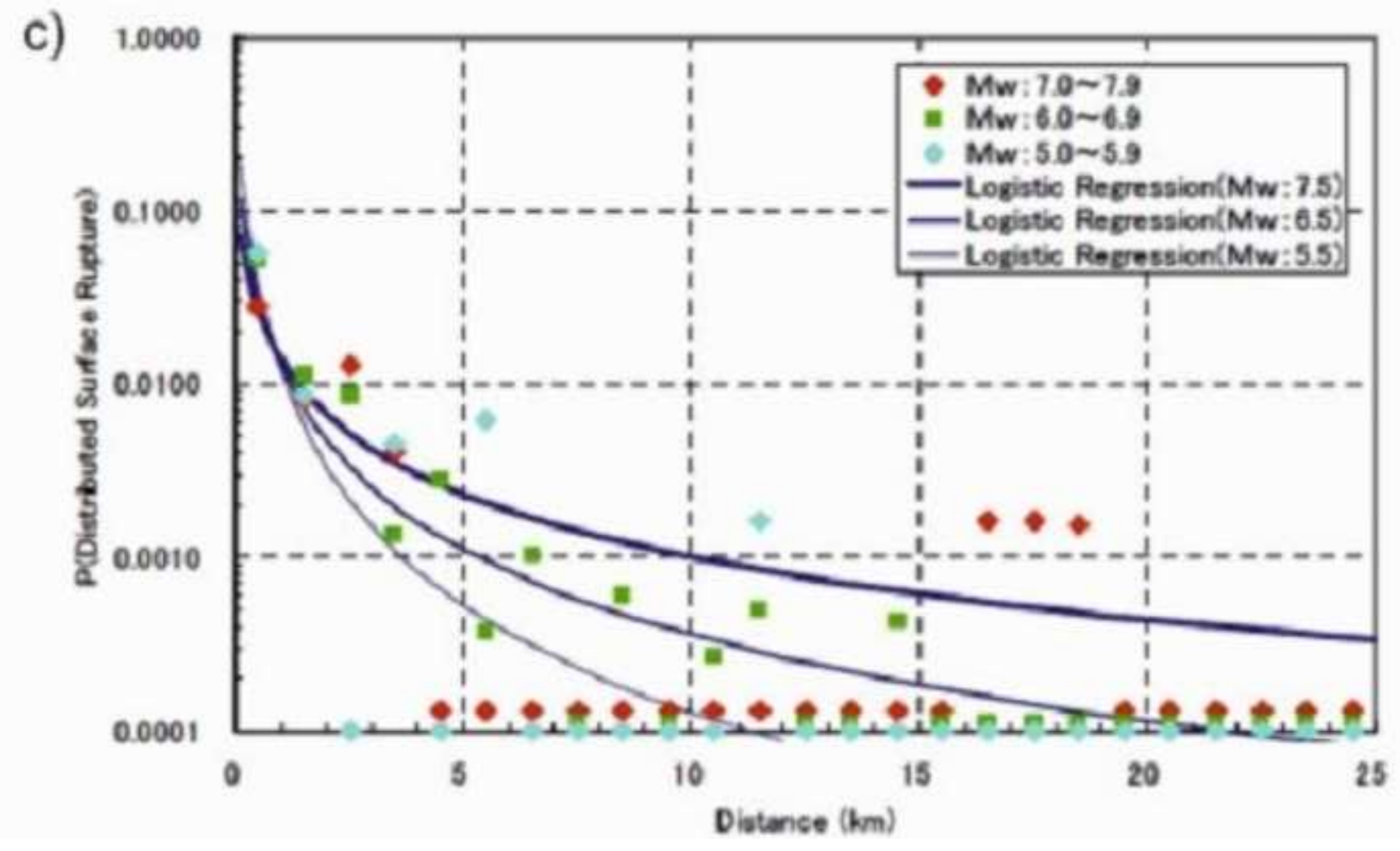

Clek here to download high resolution inage 
Figure 2.4

Click here to download high resolution image

a) A Distance from fault trace (meters)

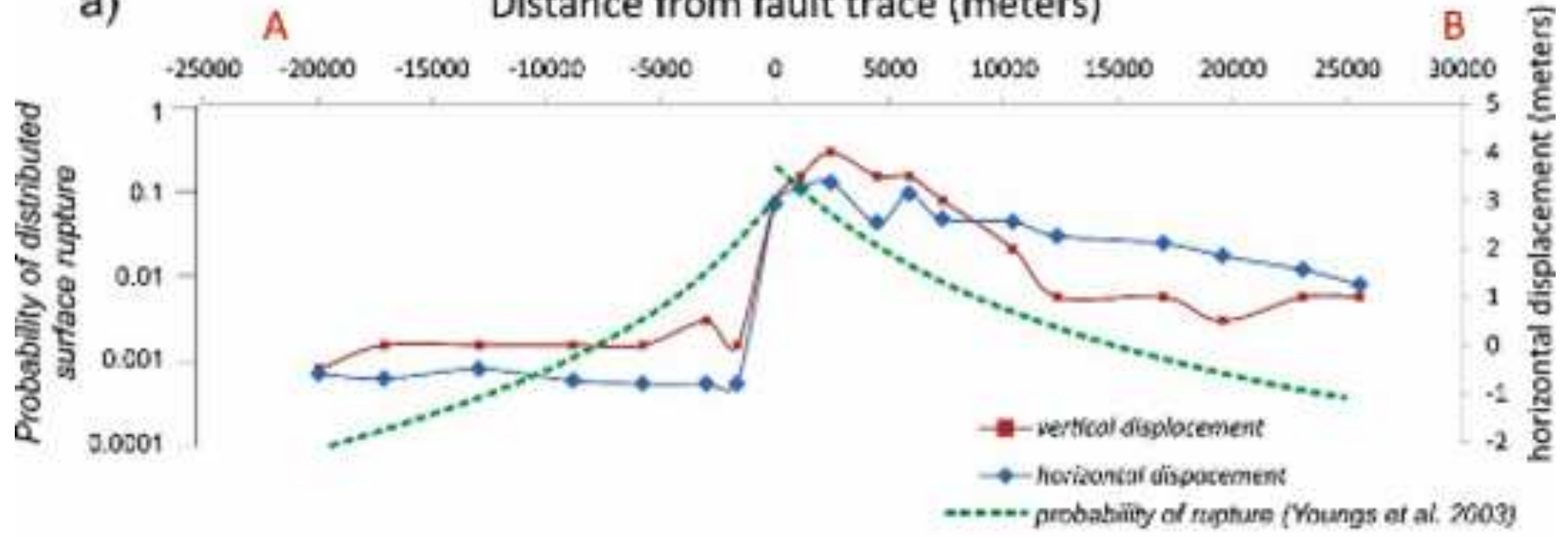

b)

Kashmir earthquake Mw 7.6 (Thrust)

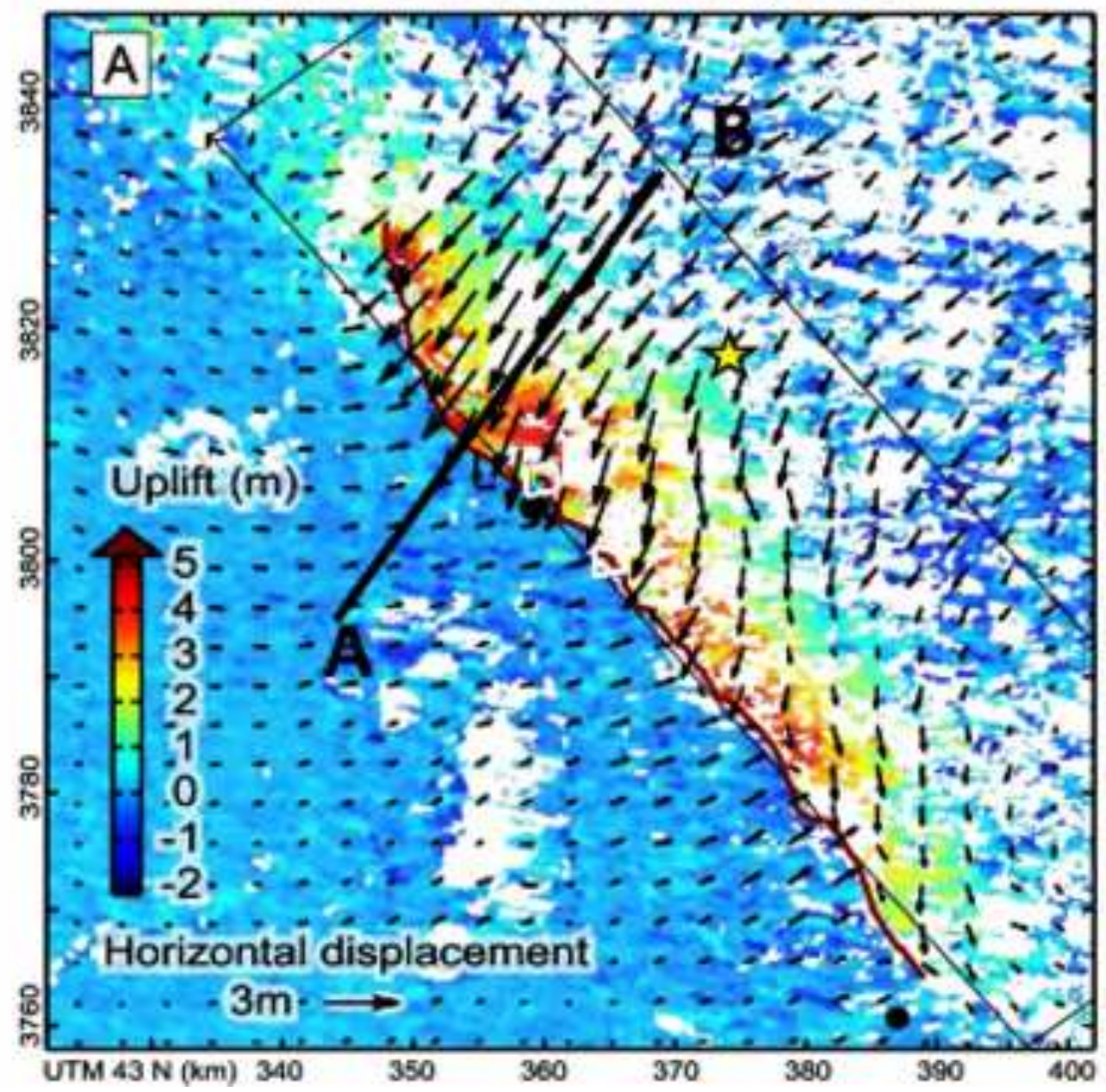


a)
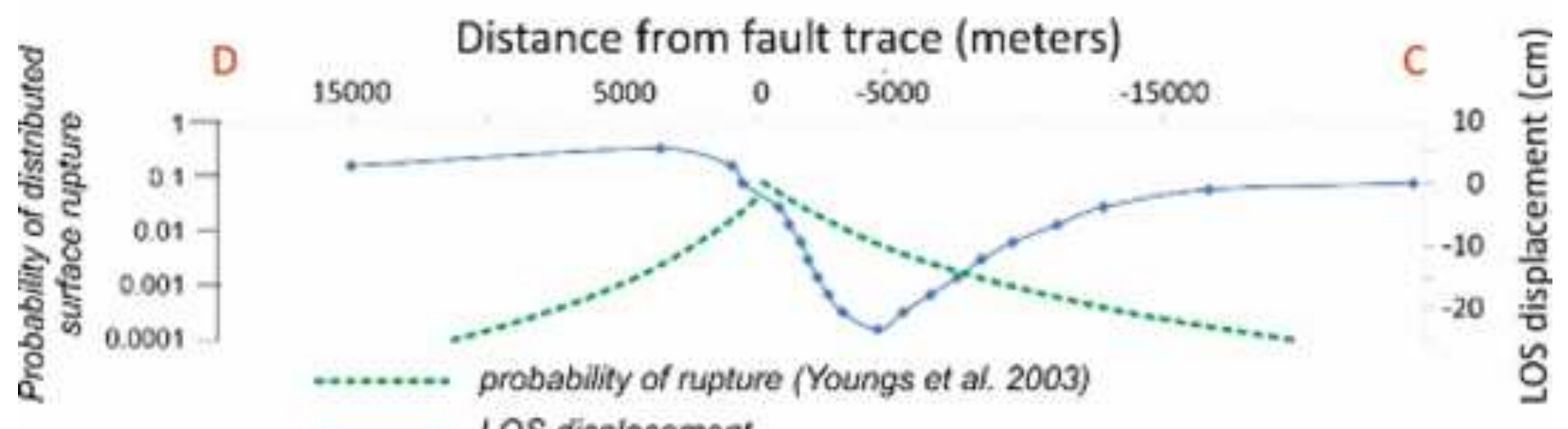

b)

L'Aquila earthquake Mw 6.3 (Normal fault)

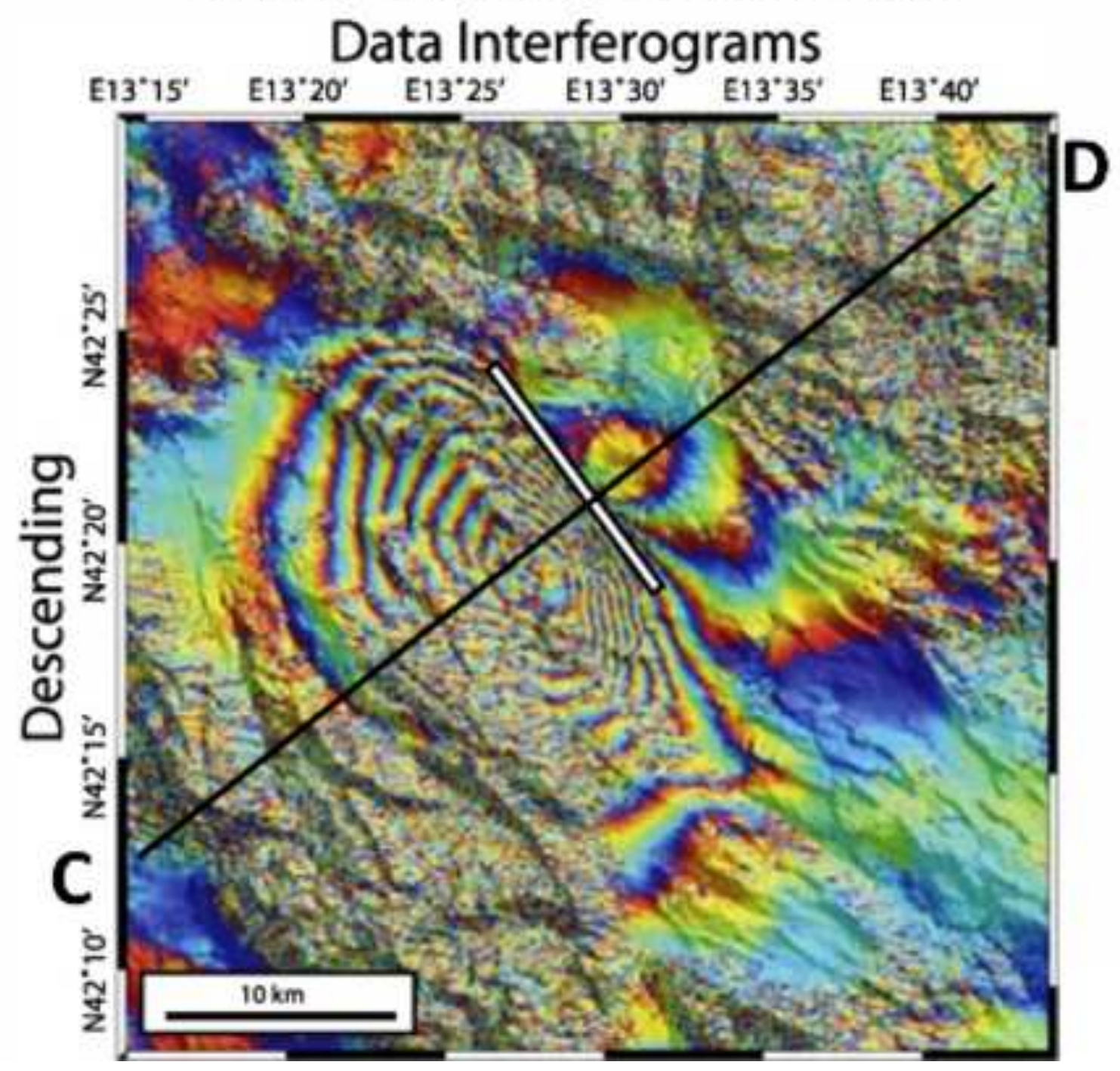




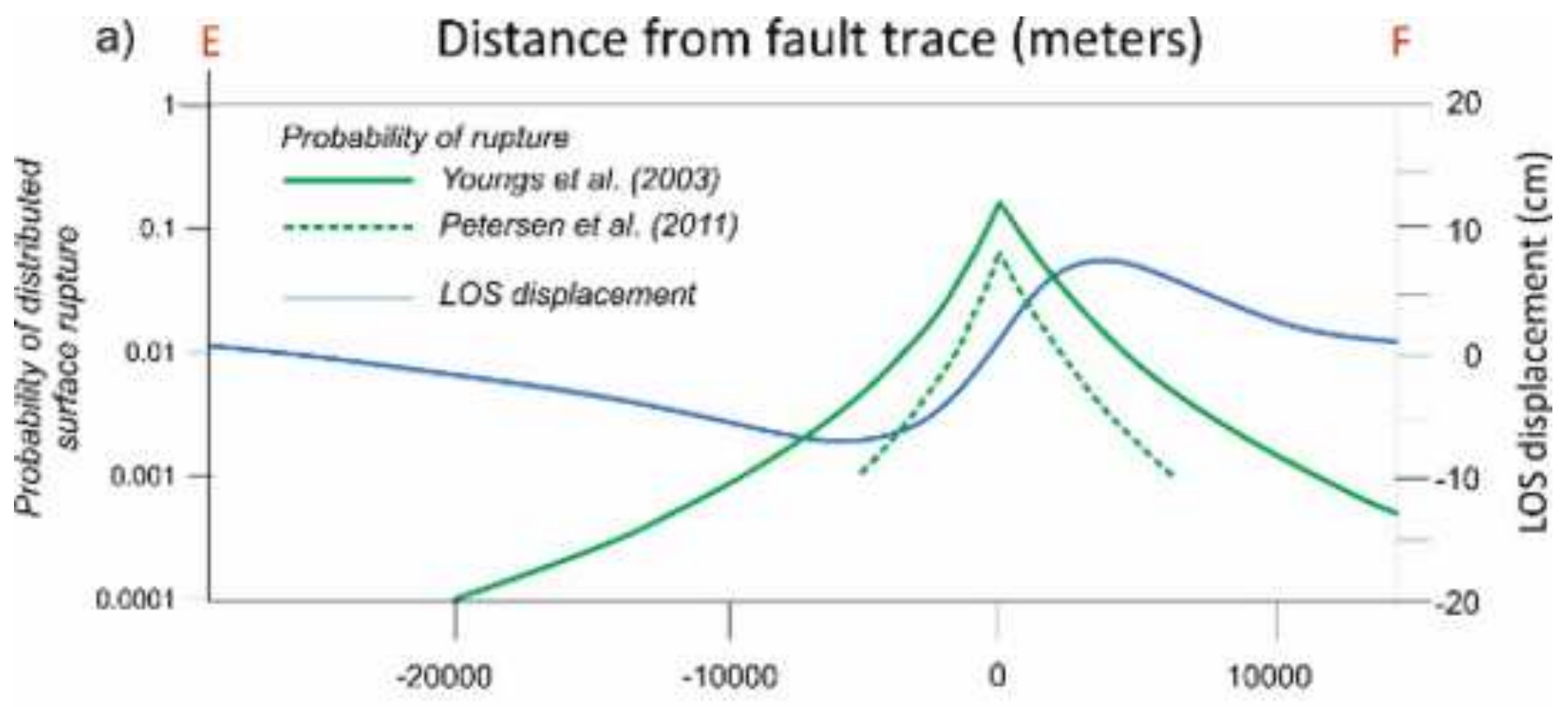

b)

Al Hoceima Mw 6.5 (Strike slip fault)

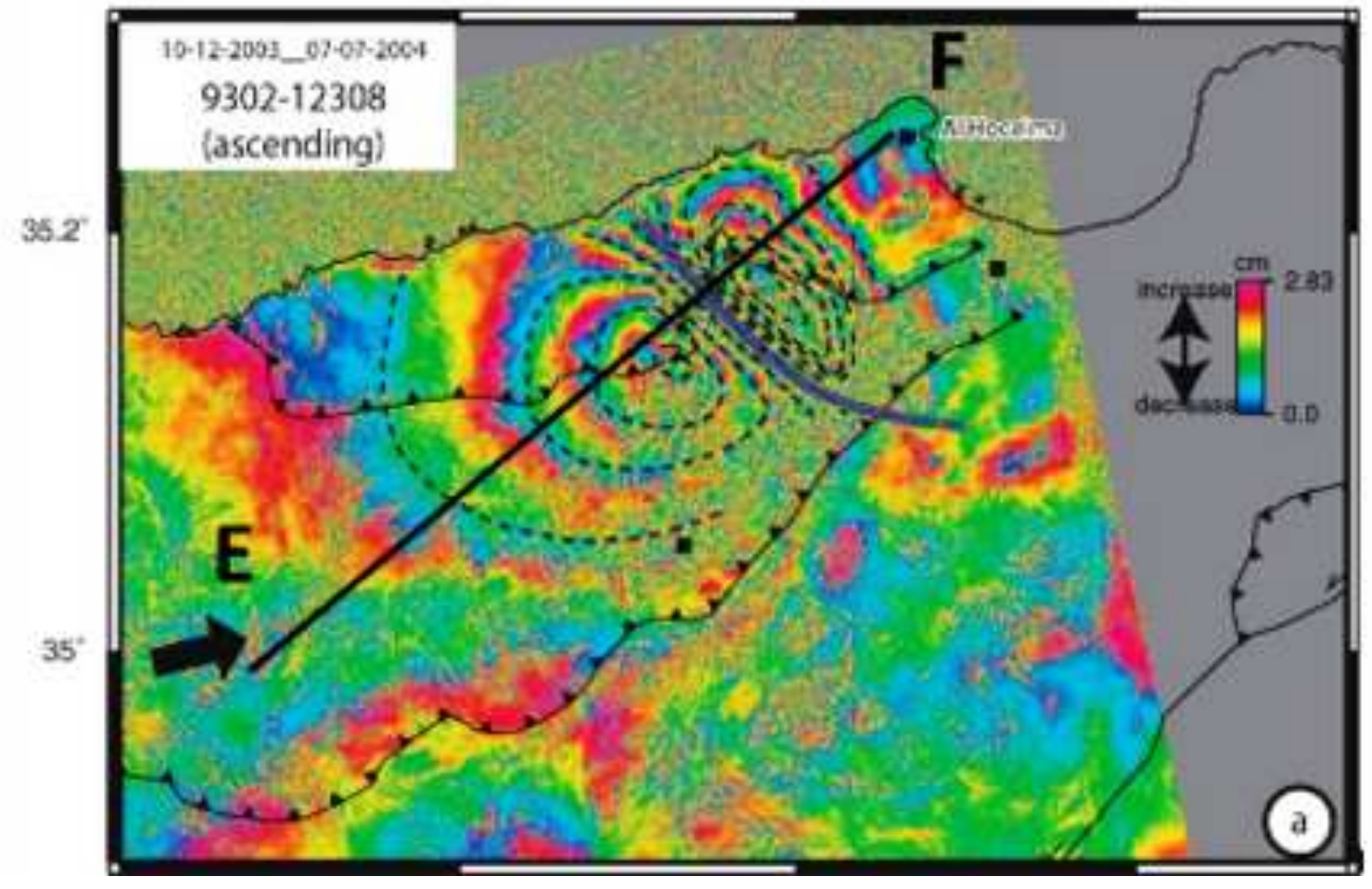




\section{7}

Click here to download high resolution image

a)

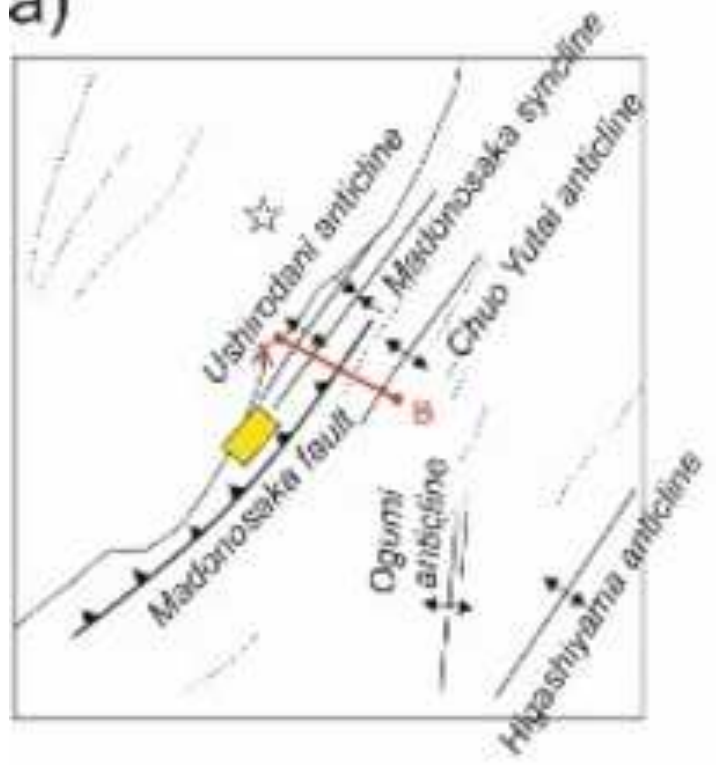

d)

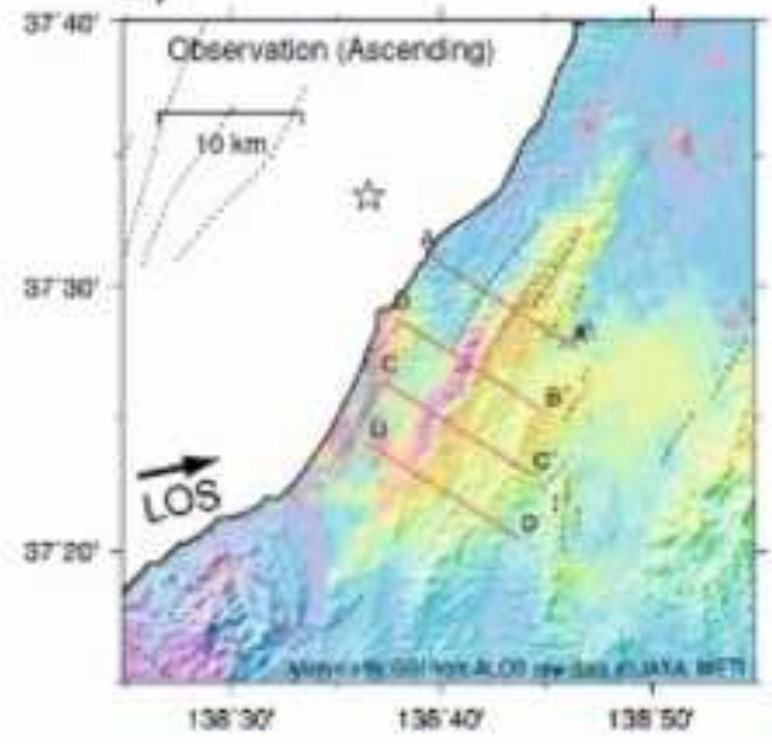

b)

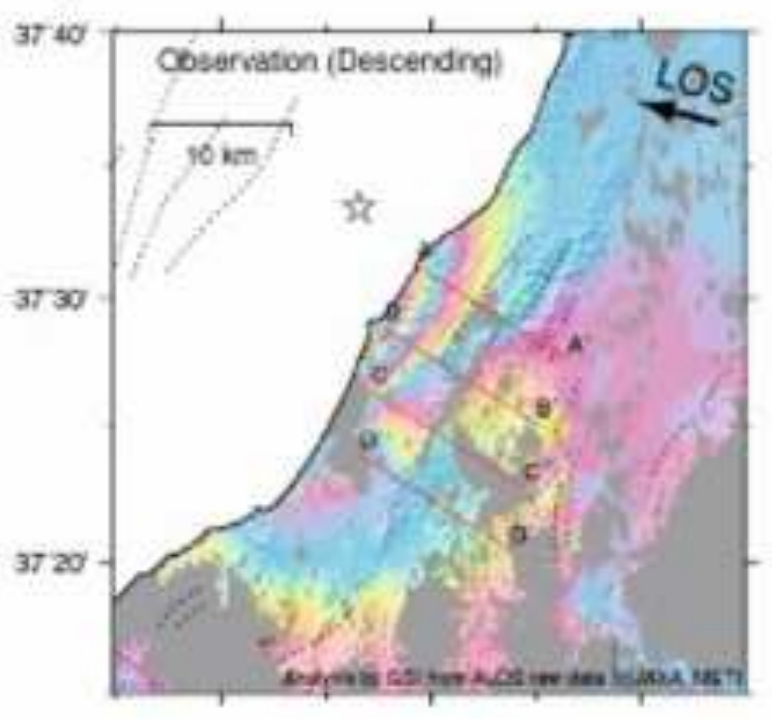

c)

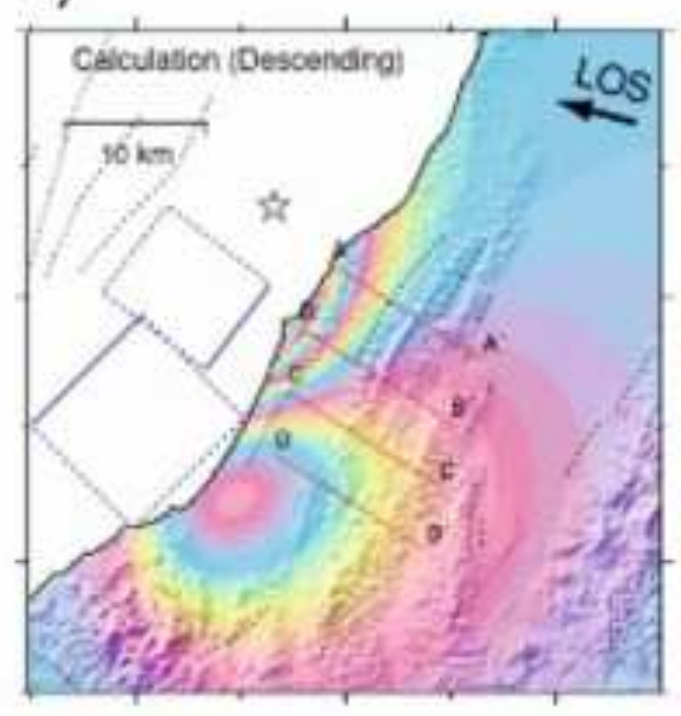

e)

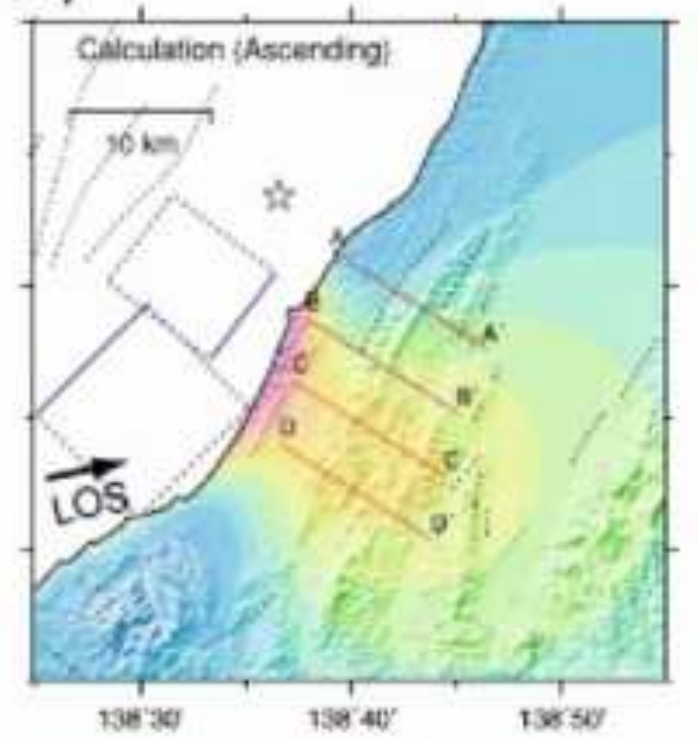


Figure 2.8
Click here to download high resolution image
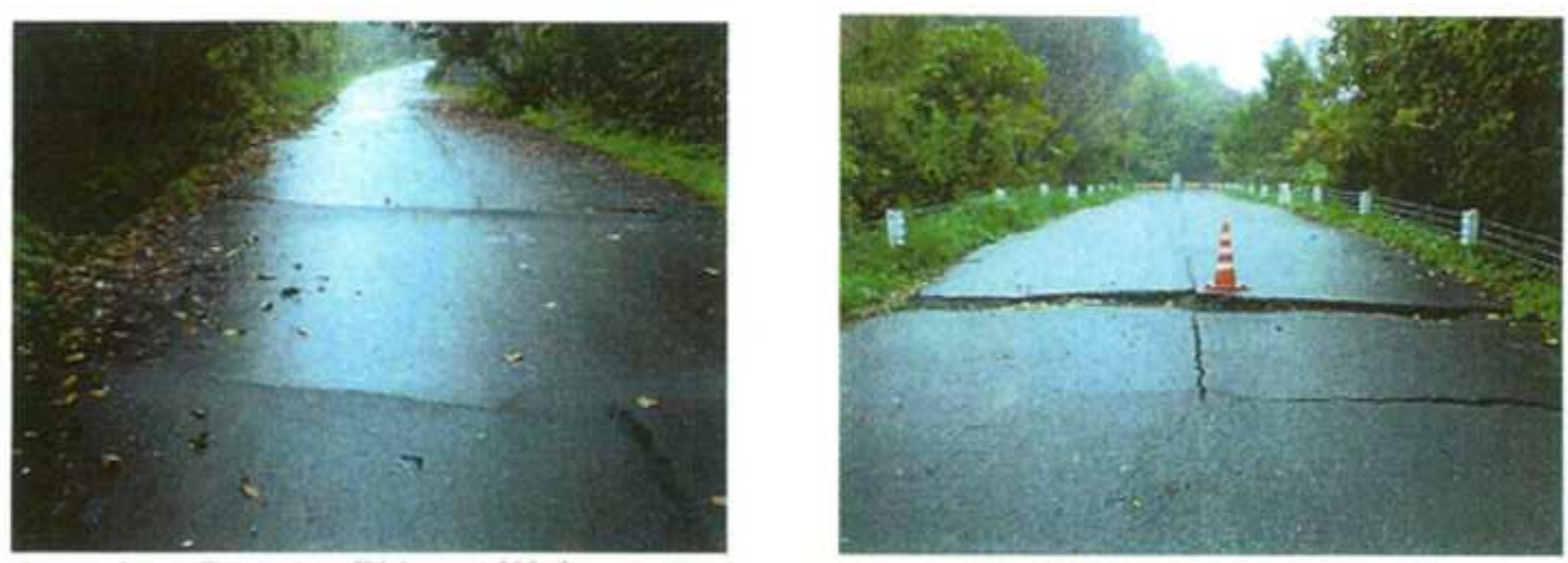
Click here to download high resolution image

a)
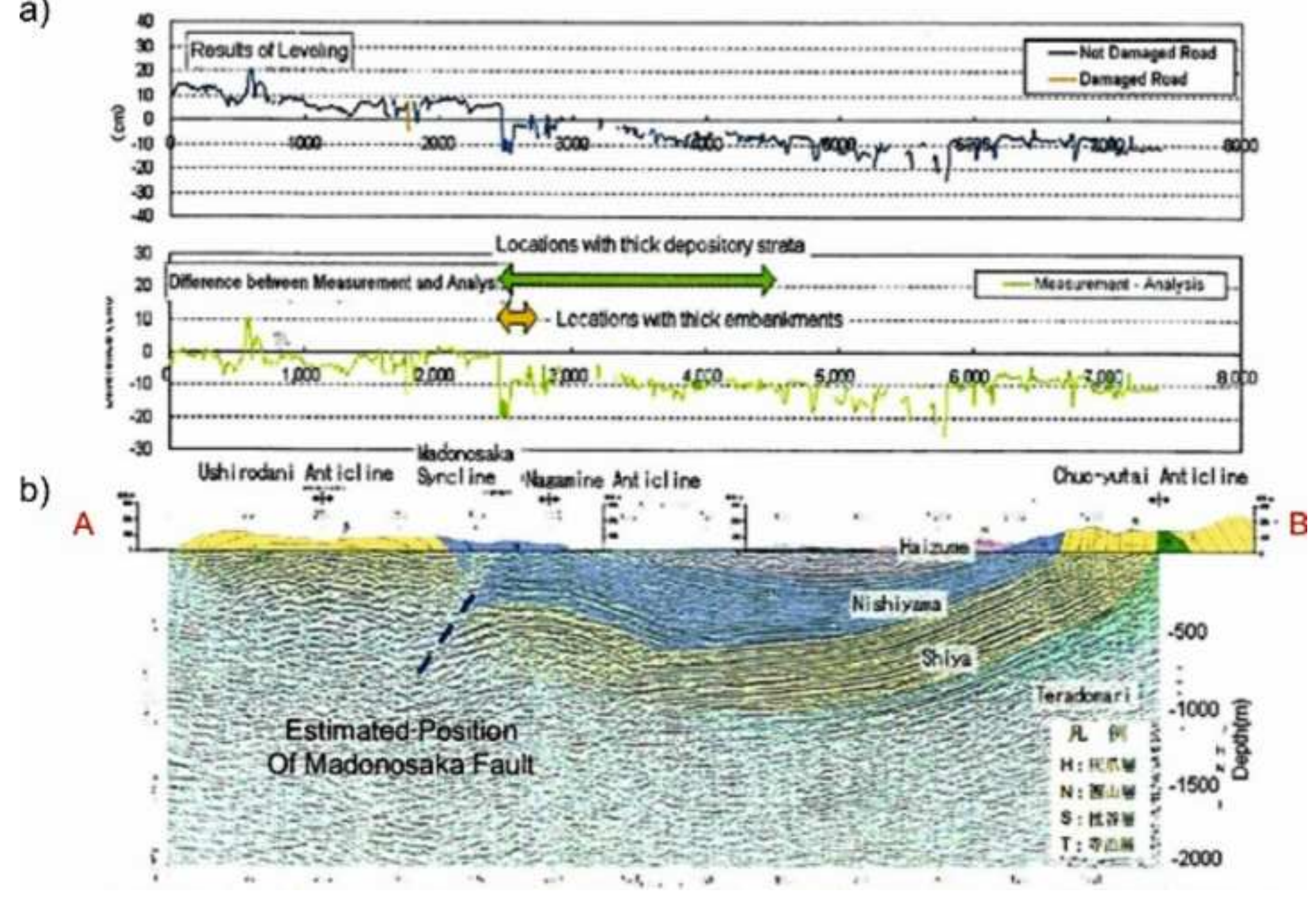

b) $=$

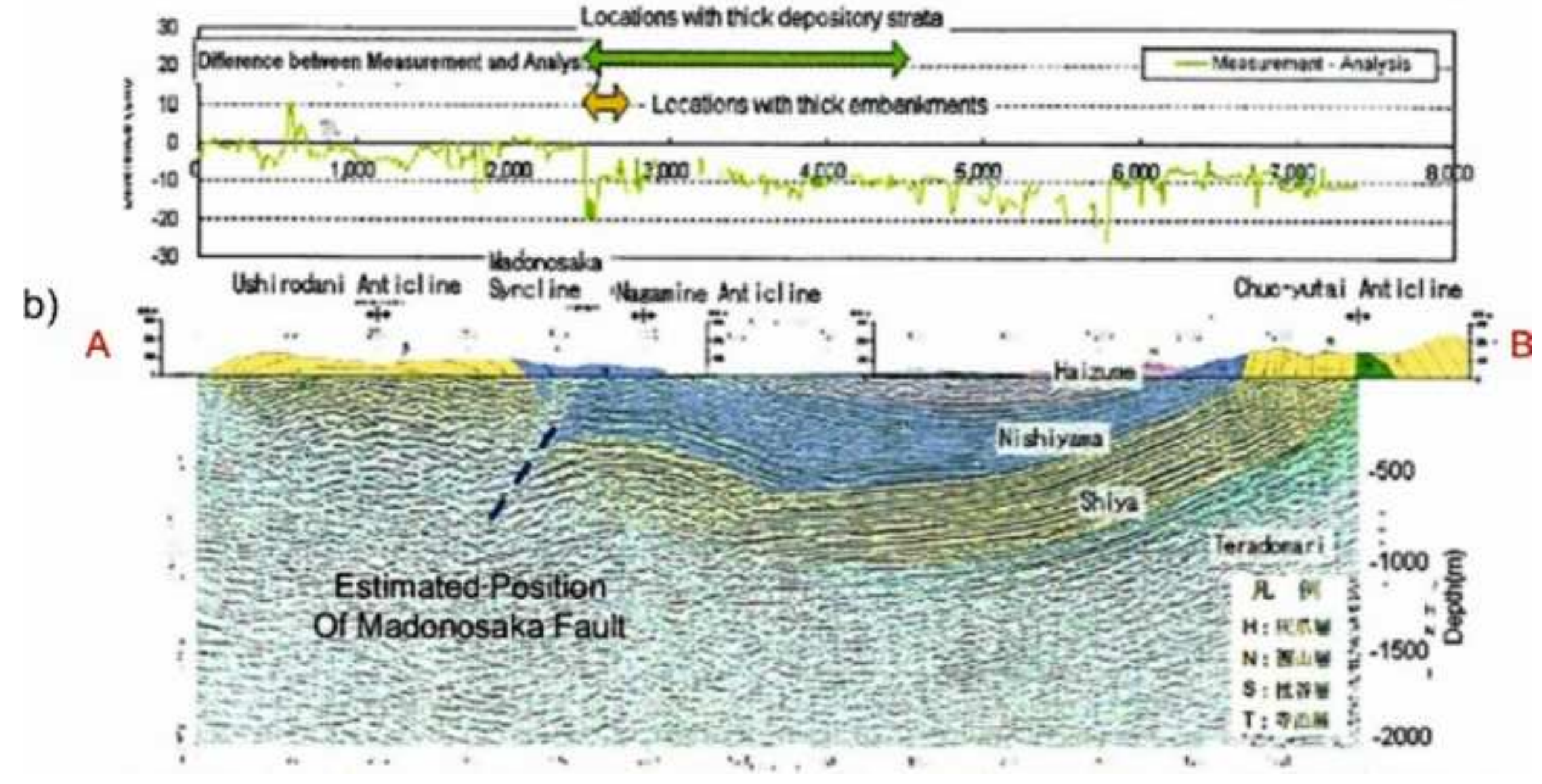


Click here to download high resolution image
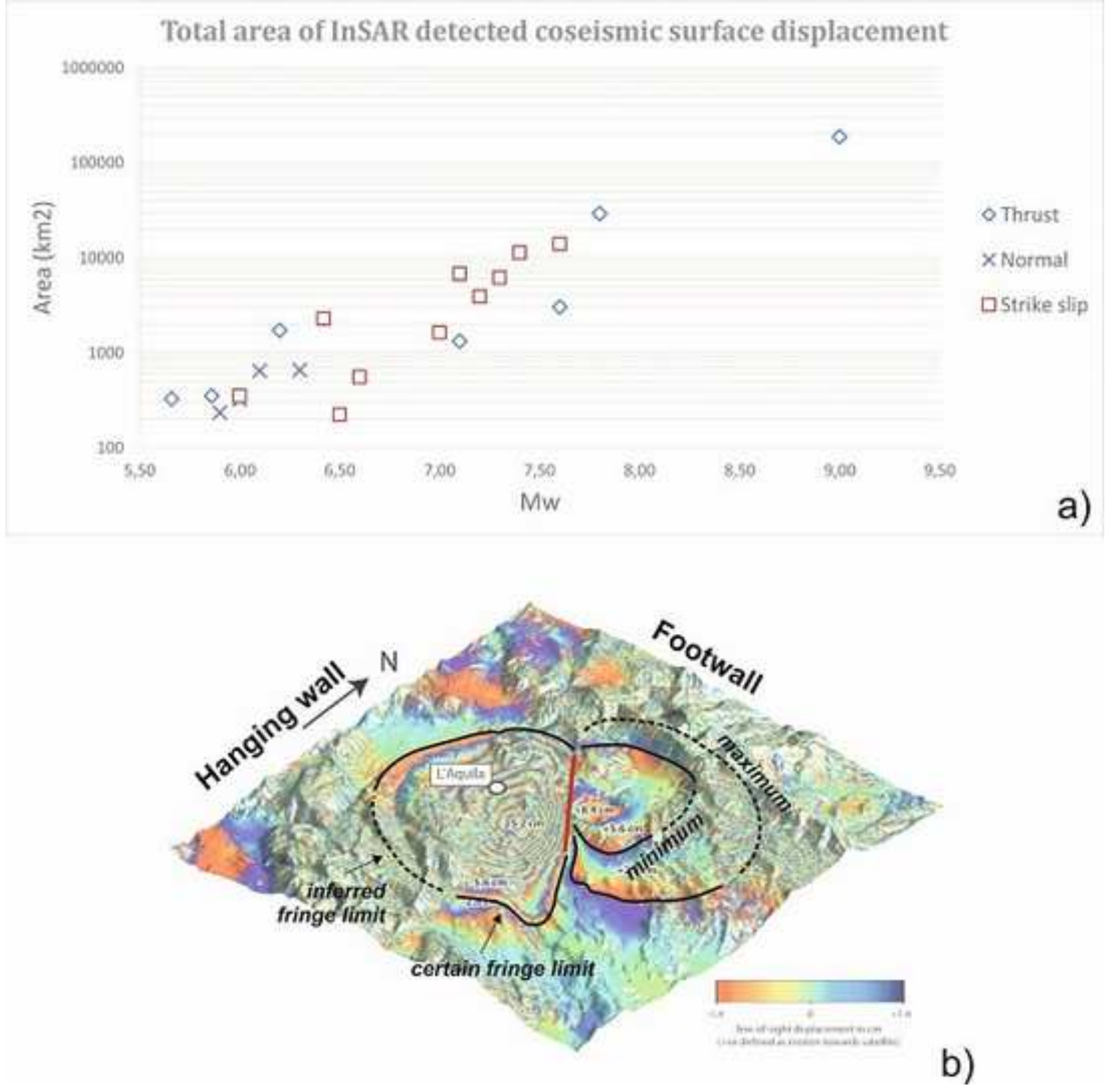

b) 


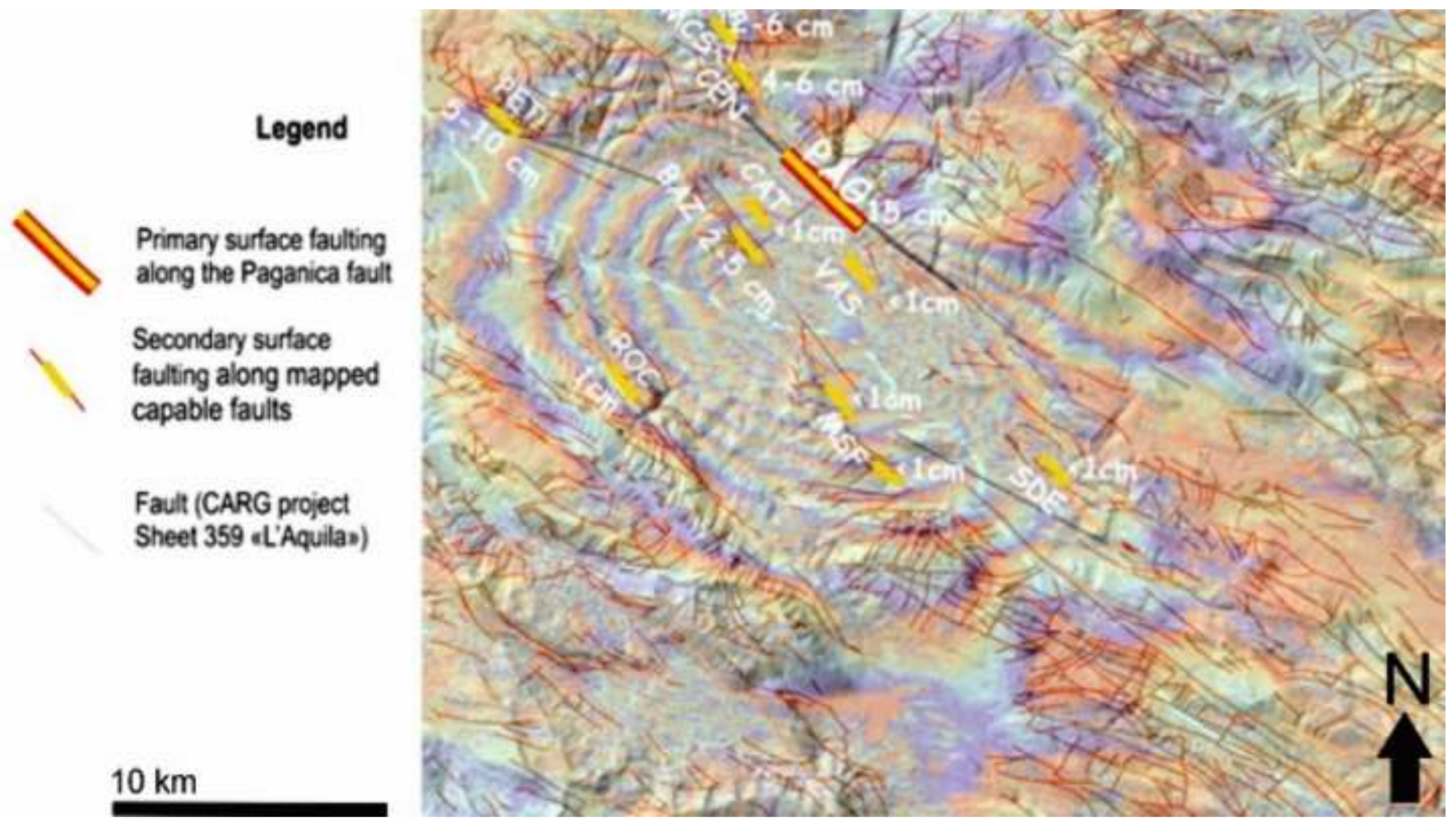

Secondary surface faulting along mapped capable faults

Fault (CARG project Sheet 359 aL'Aquilas)

$10 \mathrm{~km}$

Primary surface faulting

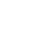


Click here to download high resolution image
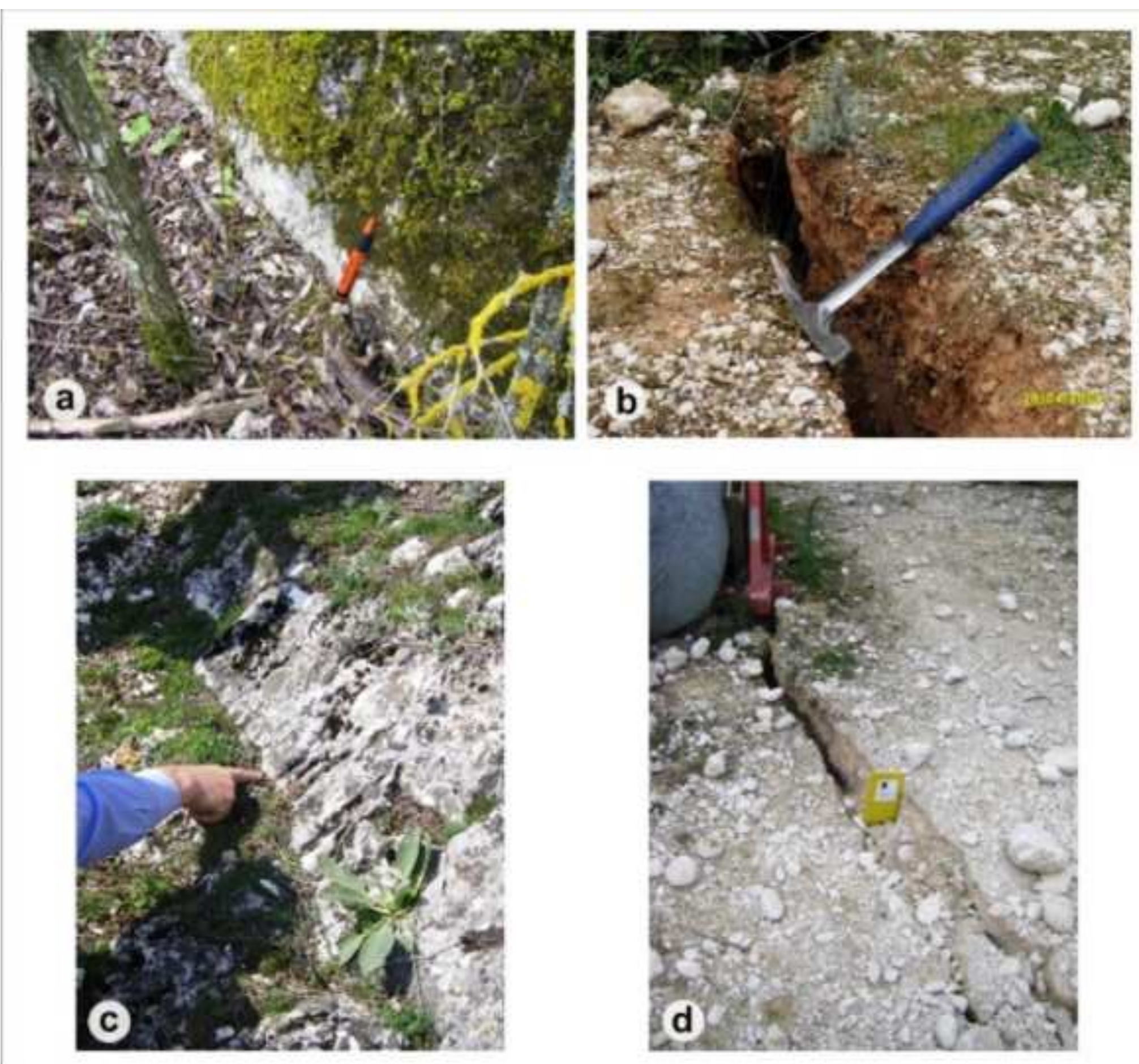
Click here to download high resolution image

a)

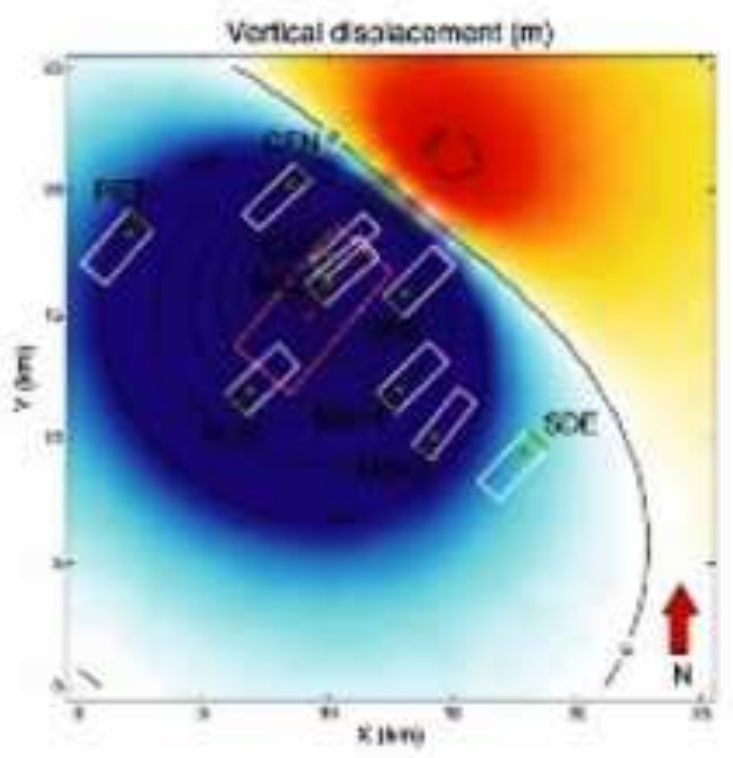

b)

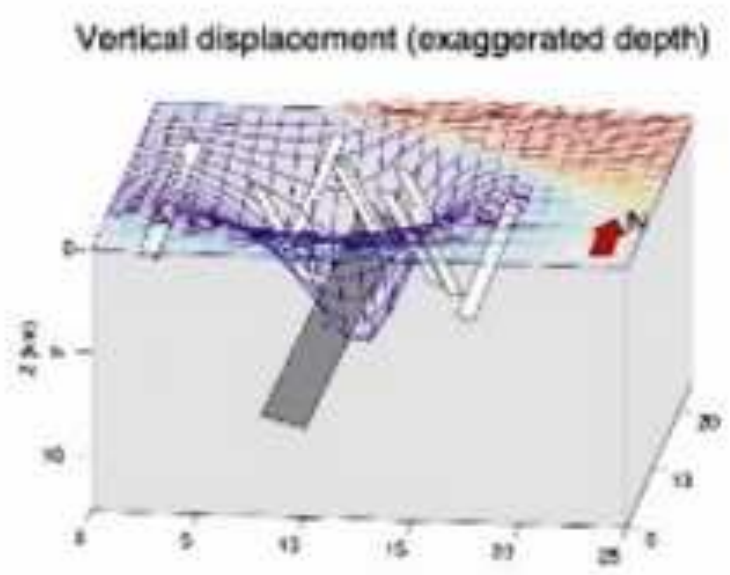

c)

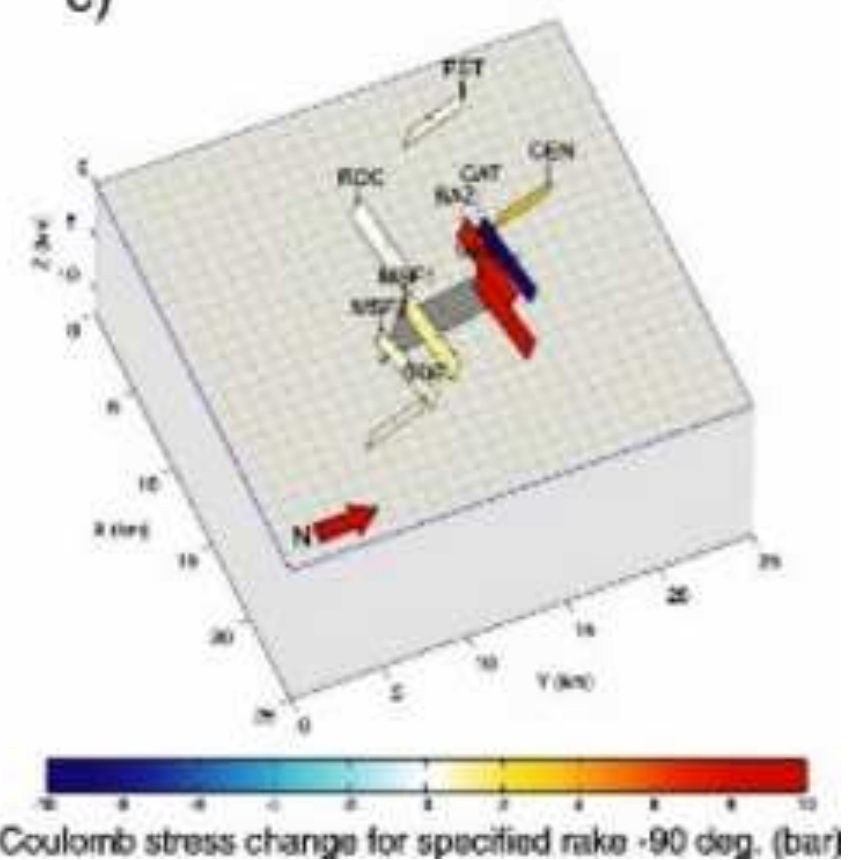


Figure 3.4
Click here to download high resolution image

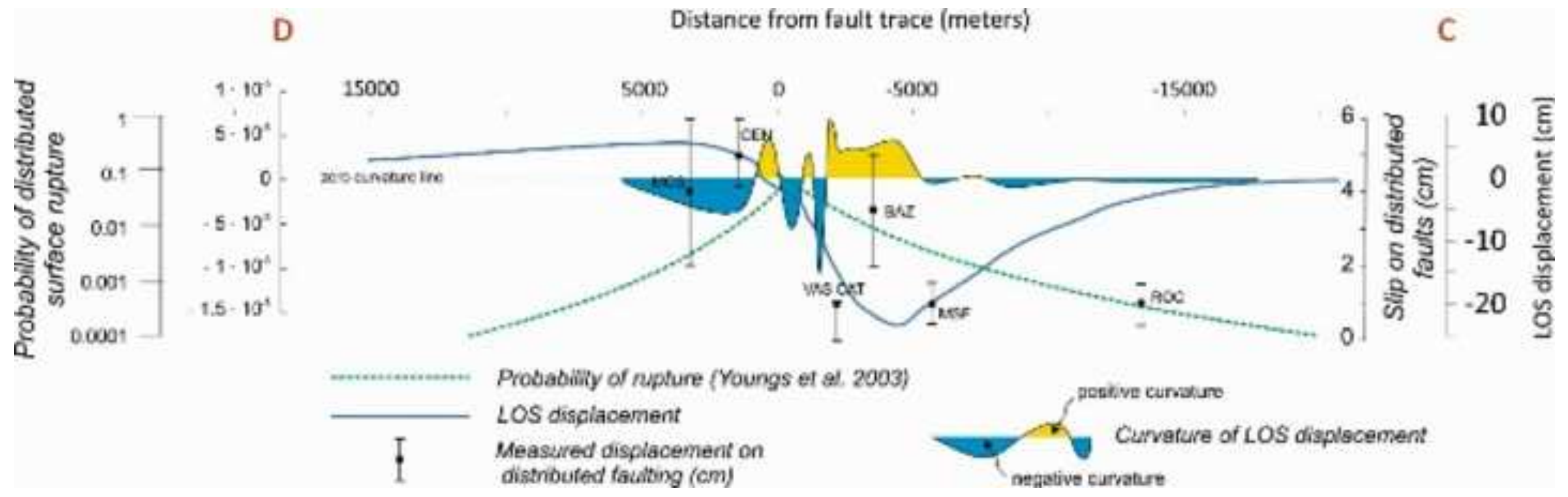


Figure 4.1

Click here to download high resolution image

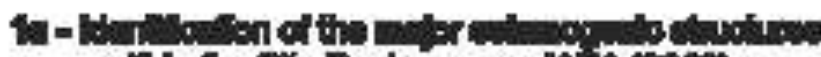

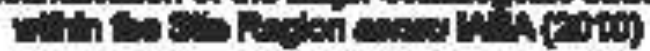<smiles>[AlH2]</smiles>

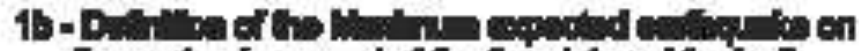

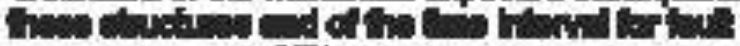

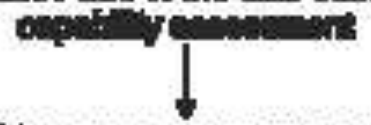

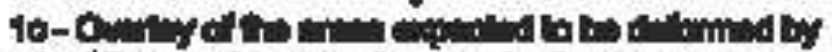
beth of thm of

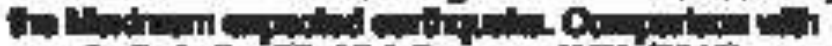

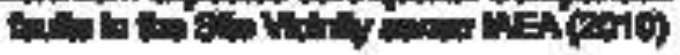

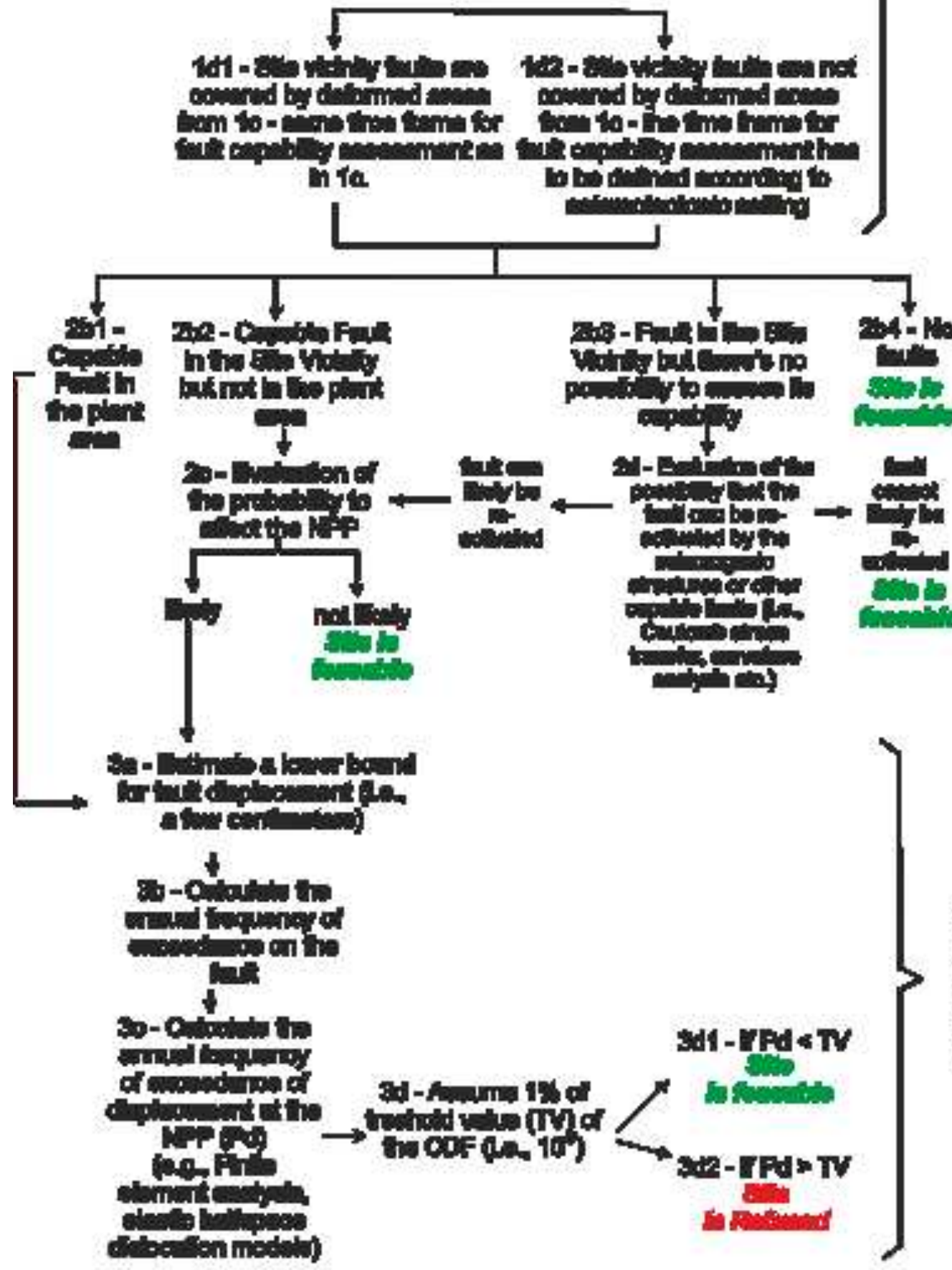

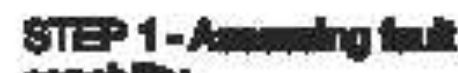
atosing
SHEP 2 - numing

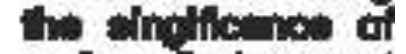

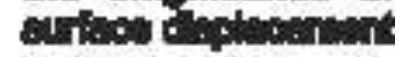

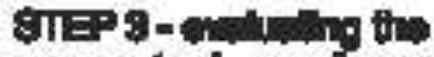
exposked suriaos dieplecement and It probability of 


\section{Figure Captions}

Figure 2.1: Probability curves for primary surface rupture for all slips (Youngs et al., 2003; mainly normal and strike-slip faults) and thrust faults (Moss \& Ross, 2011). Note that for a given magnitude, the probability of reverse rupture is significantly lower than that for other rupture types.

Figure 2.2: Slip on DF as a function of distance from the principal fault. Dataset for a) strike-slip faults (Petersen et al., 2011) and b) normal faults (Youngs et al., 2003).

Figure 2.3: Probability of slip for DF as a function of distance from the principal fault. Data are for a) normal faults (Youngs et al., 2003), b) strike-slip faults (Petersen et al., 2011), and c) reverse and strike-slip faults in Japan (Takao et al., 2013).

Figure 2.4: Co-seismic surface deformation that occurred during the $2005 \mathrm{Mw} 7.6$ Kashmir Earthquake: a) plot of the horizontal and vertical displacement components and probability curve for DF (Youngs et al., 2003) versus distance from primary fault; b) map view of the modeled In-SAR-derived, unwrapped surface deformation that show vectors for azimuth and range of displacement, and the color gradient shows the vertical deformation (modified after Pathier et al., 2006).

Figure 2.5: Co-seismic surface deformation that occurred during the Mw 6.3 L'Aquila Earthquake: a) plot of the LOS displacement and probability curve for DF (Youngs et al., 2003) versus distance from primary fault; b) map view of the modeled In-SAR- derived, wrapped surface deformation (modified after Walters et al., 2009).

Figure 2.6: Co-seismic surface deformation that occurred during the Mw 6.5 Al Hoceima Earthquake: a) plot of the LOS displacement and probability curves for DF (Youngs et al., 2003; Petersen et al., 2011) versus distance from primary fault; b) map view of the modeled, InSAR-derived, wrapped surface deformation (modified after Cakir et al., 2006).

Figure 2.7: InSAR interferograms showing the displacement of the 2007 Niigataken Chuetsu-oki Earthquake: (a) Schematic structural map; the thin, dashed lines denote active fault traces (Research Group for Active Faults of Japan, 1991), and axial planes or hinge axes of synclines and anticlines are reported. The yellow rectangle indicates the approximate location of observed secondary faulting/fracturing (cfr. Figure 2.8). Images (b) and (d) present the interferograms formed from the descending and ascending orbit respectively; the dotted rectangle shows the fault location obtained through a best-fit model (solid line on the rectangles shows the upper edge of the fault). Images (c) and (e) are modeled interferograms calculated using the fault model (modified after Nishimura et al., 2008).

Figure 2.8: Image shows an example of the faulting/fracturing that occurred in the Kashiwasaki- Kariwa NPP site vicinity. Figure 2.7a identifies the location of the area affected by these secondary deformations.

Figure 2.9: a) Levelling measurements in the Kashiwasaki-Kariwa NPP site vicinity, across the Madonosaka Fault: b) geologic cross section of the area (Figure 2.7a gives section trace).

Figure 2.10: a) Regression between $\mathrm{Mw}$ and total area of deformation (Km2) - the recent 2016 Central Italy earthquake, not included in the regression, is also reported showing a good accordance with predicted values; b) assumed method for area calculation: typical observed versus inferred fringe limits and uncertainties in the locations of the most external coherent fringes are indicated.

Figure 3.1: Co-seismic reactivation along capable faults induced by the 2009 L'Aquila Earthquake (modified after Guerrieri et al., 2010). Red lines indicate all the mapped faults in the study area at 1:50,000 scale (CARG Project http://www.isprambiente.gov.it/Media/carg/359_LAQUILA/Foglio.html). Labels are BAZ, Bazzano fault; CAT, Colle Caticchio fault; CEN, Colle Enzano fault; MCS, Monte Castellano fault; MSF, Monte San Franco fault; PAG, Paganica fault.

Figure 3.2: Co-seismic reactivations along capable faults: a) BAZ, Fault; b) PAG, fault; c) ROC fault; d) PAG fault.

Figure 3.3: Elastic dislocation model and static stress changes caused by the L'Aquila Earthquake, modeled on the Paganica Fault parameters, as derived by Walters et al. (2009); see text for details. Map view and contouring (a) and 3D view (b) of vertical displacement at surface (in meters) and comparison with the distribution of secondary faults that experienced offset during the L'Aquila Earthquake. White boxes in (a) represent the map projection of dipping planes, arrows indicate the dip direction, and the red box indicates the primary Paganica fault. A 3D view of the static stress change induced by the L'Aquila Earthquake on the considered secondary faults is provided in (c); positive stress changes induce the considered fault to slip.

Figure 3.4: InSAR-derived LOS displacements across the area affected by the L'Aquila Earthquake (cfr. Figure 2.5 for section trace) plotted against curves for conditional probability of slip on DF (Youngs et al., 2003) and observed displacements measured soon after the main shock. See the text for further comments.

Figure 4.1: Proposed workflow for the assessment of primary and distributed fault displacement hazard in the case of NPP. 